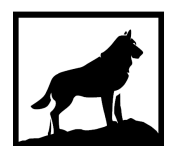

Michigan

Technological

1 8 8 5 University
Michigan Technological University

Digital Commons @ Michigan Tech

2017

\title{
ASSESSING GROWTH, YIELD, AND CARBON DYNAMICS IN UPPER GREAT LAKES JACK PINE AND HYBRID POPLAR MANAGED FOR BIOMASS PRODUCTION
}

Ashlee Baker Lehner

Michigan Technological University, ashleeb@mtu.edu

Copyright 2017 Ashlee Baker Lehner

Recommended Citation

Baker Lehner, Ashlee, "ASSESSING GROWTH, YIELD, AND CARBON DYNAMICS IN UPPER GREAT LAKES JACK PINE AND HYBRID POPLAR MANAGED FOR BIOMASS PRODUCTION", Open Access Master's Thesis, Michigan Technological University, 2017.

https://doi.org/10.37099/mtu.dc.etdr/317

Follow this and additional works at: https://digitalcommons.mtu.edu/etdr

Part of the Forest Management Commons 


\title{
ASSESSING GROWTH, YIELD, AND CARBON DYNAMICS IN UPPER GREAT \\ LAKES JACK PINE AND HYBRID POPLAR MANAGED FOR BIOMASS PRODUCTION
}

\author{
By \\ Ashlee B. Lehner
}

\begin{abstract}
A THESIS
Submitted in partial fulfillment of the requirements for the degree of MASTER OF SCIENCE

In Forestry
\end{abstract}

MICHIGAN TECHNOLOGICAL UNIVERSITY

2017

(C) 2017 Ashlee B. Lehner 

This thesis has been approved in partial fulfillment of the requirements for the Degree of MASTER OF SCIENCE in Forestry.

School of Forest Resources and Environmental Science

\author{
Thesis Advisor: $\quad$ Dr. Robert E. Froese
}

Committee Member: Dr. Nan C. Pond

Committee Member: Dr. Matthew C. Kelly

School Dean: $\quad$ Dr. Terry L. Sharik 

To my loving and supportive husband and family. 



\section{Table of Contents}

List of Figures and Tables ...................................................................... ix

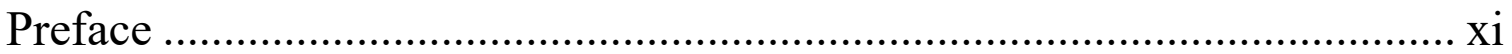

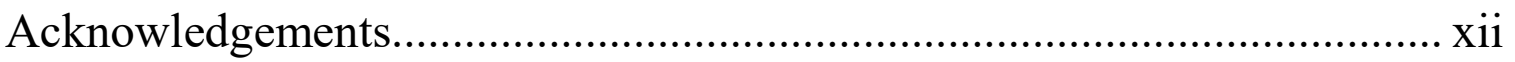

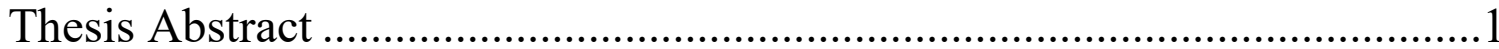

1 Site index curves for hybrid poplar in the Upper Great Lakes................2

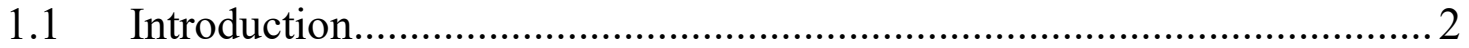

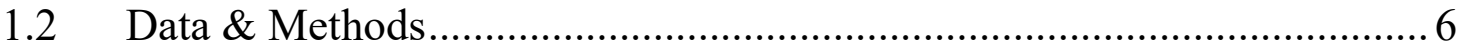

1.2.1 Base Model Development.................................................................... 11

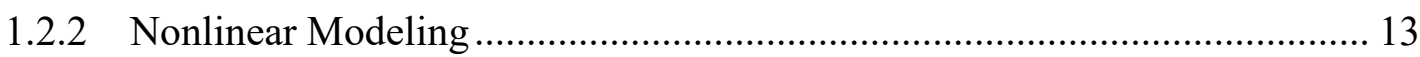

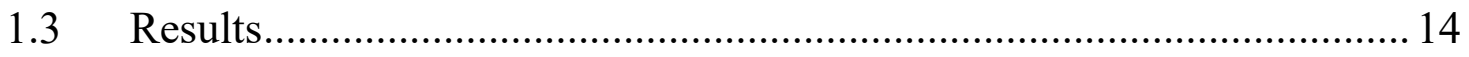

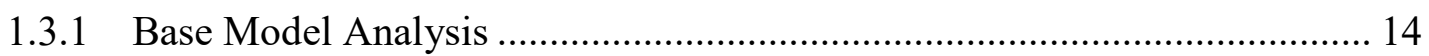

1.3.2 Application of Nonlinear Model............................................................ 18

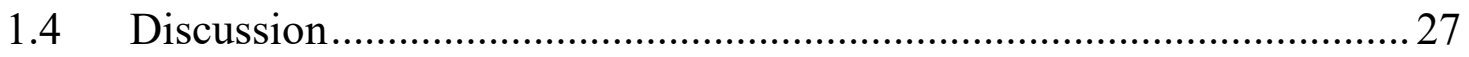

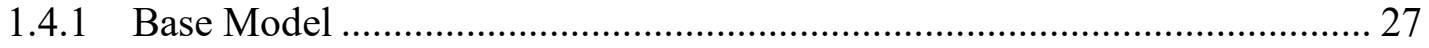

1.4.2 Nonlinear Mixed Effects Model .......................................................... 28

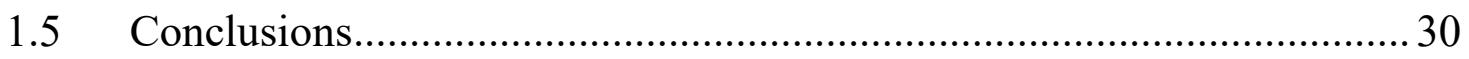

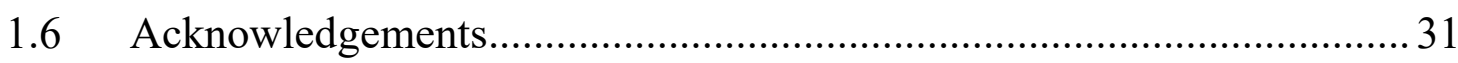

2 Analysis of alternative silvicultural prescriptions in Kirtland's warbler habitat, thinning scenario provides improved GHG emissions and production

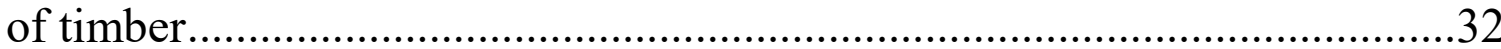

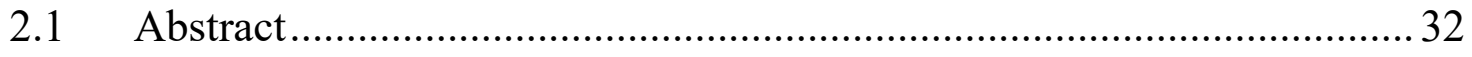

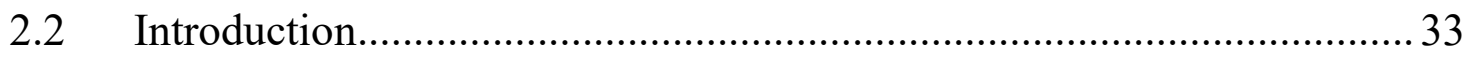

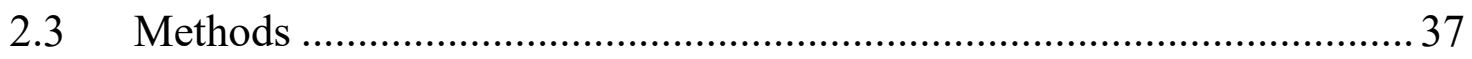

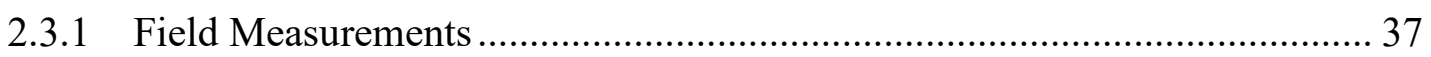

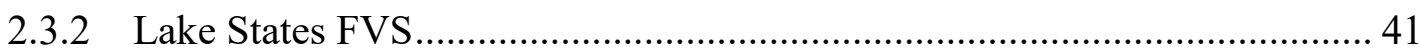

2.3.3 Simulation of BAU and Alternative Management Regimes......................... 43

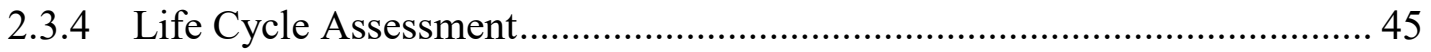

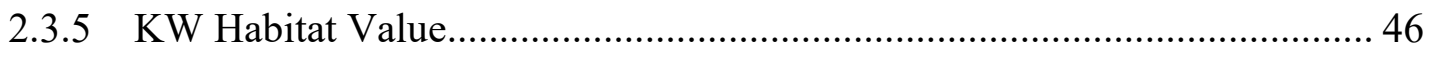

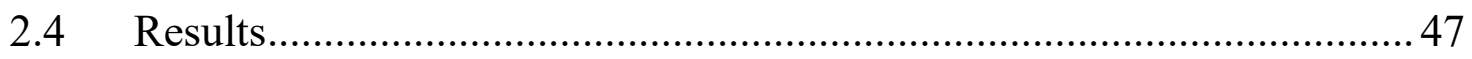

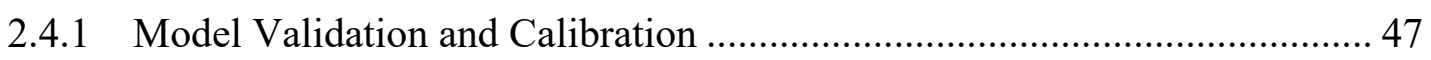

2.4.2 BAU and Alternative Silvicultural Regimes.................................................. 48

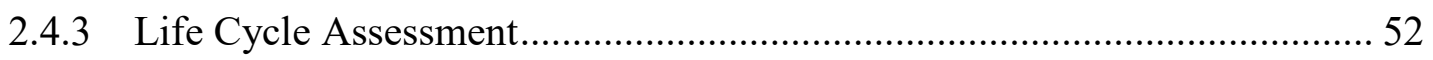


2.4.4 Net Carbon .................................................................................... 53

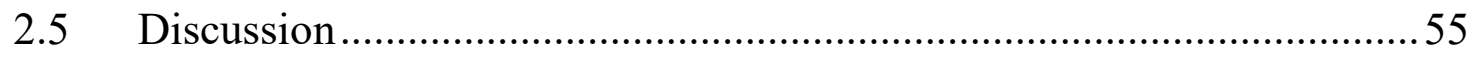

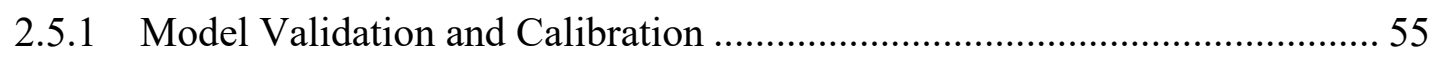

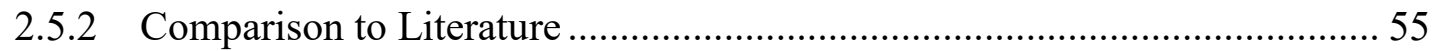

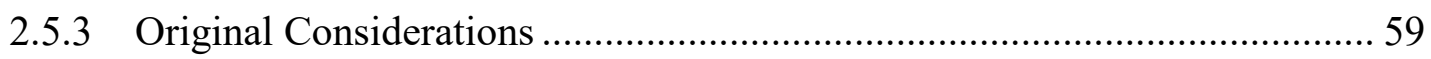

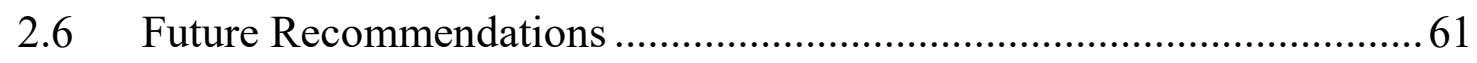

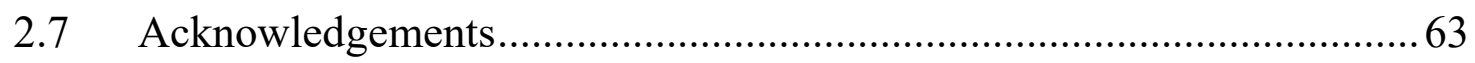




\section{List of Figures and Tables}

Figure 1.1. Location plantations within the Michigan Technological University Hybrid

Poplar Network in the Upper Peninsula of Michigan, four plantations total.

Copyright: (C) 2014 National Geographic Society, i-cubed.

Figure 1.2. Location plantations within the Michigan Technological University Hybrid

Poplar Network in the Lower Peninsula of Michigan, seven plantations total.

Copyright: (C) 2014 National Geographic Society, i-cubed. 8

Figure 1.3. Base model curve shape for four models tested with height observations of dominant trees within each treatment unit. Site index value shown is 8 meters at 10years post-planting. 15

Figure 1.4. Residual plots for (a) Schumacher $1 \mathrm{~b}$ (shown as fitted $\ln (\mathrm{S})$ vs. residual

$\ln (\mathrm{S}))$, (b) Schumacher 1c, (c) Bailey \& Clutter, and (d) Chapman-Richards.......... 16

Figure 1.5. Quantile-quantile (QQ) plot for (a) Schumacher 1b, (b) Schumacher 1c, (c)

Bailey \& Clutter, and (d) Chapman-Richards. 17

Figure 1.6. Generalized site index curves (12, 8, and 4 meters at 10 years) for Michigan

Technological University Hybrid Poplar Network plotted with dominant trees..... 19

Figure 1.7. Site index curves $(12,8$, and 4 meters at 10 years) for two hybrid types in

Michigan Technological University Hybrid Poplar Network.

Figure 1.8. Height values for hybrid types of NM6 and DN34 within the Michigan

Technological University Hybrid Poplar Network.

Figure 1.9. Site index curves (12,8, and 4 meters at 10 years) for Michigan

Technological University Hybrid Poplar Network at three different planting densities.

Figure 1.10. Height values for treatment unit densities of 3.3, 6.1, and $8.9 \mathrm{~m} 2 /$ tree within

the Michigan Technological University Hybrid Poplar Network........................... 23

Figure 1.11. Site index curves (10, 8, and 4 meters at 10 years) for Michigan

Technological University Hybrid Poplar Network for three different stock types... 24

Figure 1.12. Height values for cutting, pole, and rooted stock types for Michigan

Technological University Hybrid Poplar Network. 25

Figure 1.13. Comparison of generalized nonlinear model to short rotation eastern cottonwood (Cao and Durand 1991) and poplar in Sweden (Johansson 2011), site index value shown is 8 meters at 10 years post planting.

Figure 2.1. Sampling locations of natural and plantation jack pine stands across Michigan. Source: Little, Jr., E.L. 1999. Atlas of United States Trees. U.S. Geological Survey. Digital Version 1.0. Copyright: (C) 2014 National Geographic Society, i-cubed. 38 
Figure 2.2. Example of digitized openings within jack pine plantation managed for Kirtland's warbler breeding habitat. Sources: Esri, DigitalGlobe, GeoEye, i-cubed, USDA FSA, USGS, AEX, Getmapping, Aerogrid, IGN, IGP, swisstopo, and the GIS User Community.

Figure 2.3. System boundary for jack pine plantation life cycle assessment. 45

Figure 2.4. LS-FVS model stand attributes, (a) trees per hectare, (b) basal area, and (c) quadratic mean diameter, prediction plotted against Rothstein et al. (unpublished, 2016) chronosequence data in Lower Peninsula of Michigan.

Figure 2.5. Forest carbon pools modeled by LS-FVS across four management regimes in low and high productivity stands.

Figure 2.6. Merchantable product carbon pools simulated by LS-FVS with low and high productivity estimates across four management regimes.

Figure 2.7. Carbon emitted and stored, as simulated by LS-FVS, with low and high site productivity values across four management regimes.

Figure 2.8. Time to carbon parity for carbon fluxes in thinning and short rotation regimes within low and high productivity stands compared to manual regeneration BAU... 54

Table 1.1. Site descriptions for plantations in the Michigan Technological University Hybrid Poplar Network.

Table 1.2. Average planting height for each stock type across all years planting occurred across the Michigan Technological University Hybrid Poplar Network.

Table 1.3. Number of observations for dominant individuals in each hybrid, spacing, and stock type. 11

Table 1.4. Coefficients for fitted equations $1.1-1.4$................................................ 15

Table 1.5. Evaluation statistics for the four site index base models tested...................... 18

Table 1.6. Summary of step-wise forward nonlinear mixed effects model analysis....... 26

Table 2.1. Stand characteristics for the sampled jack pine stands.

Table 2.2. Summary of silvicultural management for all regimes in both productivity classes.

Table 2.3. Forest products per hectare in low and high productivity stands across four management regimes.

Table 2.4. Percent usable KW habitat (stand age between 5-20 years) for four management regimes in low and high productivity stands. 


\section{Preface}

Currently no results presented here have been submitted or accepted or under any copyright. The detail of collaboration for each chapter is as follows:

Site index curves for hybrid poplar in the Upper Great Lakes.

All figures, tables, and writing were completed by Ashlee Lehner. Direction and edits were provided by Robert Froese and Nan Pond.

Analysis of alternative silvicultural prescriptions in Kirtland's warbler habitat, thinning scenario provides improved GHG emissions and production of timber.

All figures, tables, and writing were completed by Ashlee Lehner. Direction, edits, revisions were provided by Robert Froese, Nan Pond, and Matt Kelly.

These two chapters will be further edited and submitted to a peer-reviewed journal at a future date. 


\section{Acknowledgements}

I would like to thank USDA Agricultural and Food Research Initiative (AFRI) and poplar funding sources of Wolverine Energy, Department of Energy, and Michigan Technological University. Without the assistance from these organizations I could not have accomplished so much in the last two years. It is this assistance that allowed me to present my research at the Society of American Foresters National Convention in 2015 and 2016.

I would like to thank Dr. Robert Froese for taking me on as a graduate student and his assistance in completing my research. We had great conversations out in the field and traveling to many conferences. Dr. Froese believed I was capable of great work and strived to give me all the opportunities possible. I would also like to acknowledge my committee members Nan Pond and Matt Kelly for providing insight, edits, and support.

All the previous graduate students and part-time workers helped collect the many years of poplar growth measurements are owed a big thank you. Measuring hybrid poplars is tedious and time consuming and their work was crucial to development of my site index curves.

Kate Martin and Owen Soulliere of Michigan Technological University helped measure jack pine forests across Michigan all while keeping a smile and making me laugh. They spent countless hours further processing samples in the lab, for which I am very grateful. Dr. David Rothstein, Daphna Godath-Goodman, and Matt Gedritis from Michigan State University helped immensely during the field campaign in the Lower Peninsula by identifying stands to sample and participating in field measurements.

Thank you to the Michigan Department of Natural Resources, Michigan Technological University, and Weyerhaeuser for allowing us to destructively sample in their forests. Allowing the destruction of trees was pivotal for calibration of our model, allowing simulations to be as accurate as possible.

I am indebted to my wonderful husband for encouraging me through this process. He was a great supporter in pursuing this degree and was my biggest cheerleader through the all the stumbles. Jesse listened to all my woes and a simple "thank you" does not express my gratitude enough. Also, thank you for the love and support from my family. My family was always a phone call away and I am grateful for always being able to count on everyone. 


\section{Thesis Abstract}

Woody biomass for use as coal-replacing bioenergy has garnered increasing interest as federal and local governments require larger portions of energy production to come from renewable sources. Woody biomass can be produced from dedicated plantations grown and harvested solely for biomass production, or non-dedicated sources such as harvest residues from traditional timber operations. The creation of site index curves for hybrid poplar were established from the Michigan Technological University Hybrid Poplar Network in the upper Great Lakes Region. These site index models are to be used for landowners to assess the predicted yield at established plantations, or possibly within spatial models to assess production across the region. Research was also conducted to assess the efficacy of biomass creation within traditional timber production techniques by utilizing non-merchantable material from jack pine (Pinus banksiana) plantations currently planted and utilized for breeding habitat by the Kirtland's warbler (KW) (Setophaga kirlandii). 


\section{Site index curves for hybrid poplar in the Upper Great Lakes}

\subsection{Introduction}

Woody biomass for use as coal-replacing bioenergy has garnered increasing interest as federal and local governments require larger portions of energy production to come from renewable sources. Woody biomass can come from dedicated plantations grown and harvested strictly for biomass production, or non-dedicated sources such as harvest residues from day-to-day timber operations. Biomass from traditional forest harvest is easier to extract since residues are generated with or without the need for renewable bioenergy. Dedicated sources, such as plantations, need to be placed in a locale that will be specialized in biomass for at least the rotation of the woody crop. One common thread for the efficacy of specialized biomass plantation is the crop's ability to be planted on marginal land that would not interfere with human or animal food production. Another major setback for implementation of short rotation biomass is the direct relation of interest in bioenergy and the cost of petroleum. As petroleum prices increase interest in bioenergy also increases, thus reducing barriers to implementation. But, when petroleum prices are diminished the interest and feasibility decline.

One such example of a dedicated short rotation woody biomass source is hybrid poplar. Hybrid poplar encompasses a large body of tree hybrids that are crosses within the Salicaceae family and in the Populus genus. Poplars have been grown in North America for years and have many uses from phytoremediation, to erosion control, and bioenergy (Isebrands and Karnosky 2001, Zalesny and Bauer 2007). Hybrid poplar has caught much attention over the last few decades due to renewed need for sustainable sources of biomass for energy and other forest products as countries see the need to mitigate the effects of climate change. Most research regarding hybrid poplar trees and plantations has centered around genetics and selecting the preferred clone for desirable characteristics such as rapid growth or increased lignin content (Goyal et al. 1999, Tuskan et al. 1999).

When implemented at large spatial scales, management of hybrid poplar for biomass must recognize a number of factors that could affect growth and yield in addition to genetic characteristics. These considerations include site selection, stock type used, 
and the density at which the trees are planted. Zalesny (2009) and Zalesny and Headlee (2015) have shown site selection and genotype influence productivity. DesRochers and Tremblay (2009) researched the effect of stock type choice on early growth and concluded that rooted, shoot-pruned stock fair better than unrooted stock within the first two growing seasons. DesRochers and Tremblay (2009) also showed that stock types without the shoot trimmed fared worse from tip dieback. Changes to individual hybrid poplar form were tested by DeBell et al. (1996), who found that total stand production was not different at increased densities. Although these characteristics have been tested separately, the inclusion of these in a yield model will highlight changes in form of growth. For implementation of growth and yield at a small plantation or large area, operational level, a site index model would be needed for a landowner to estimate expected final growth from current height.

Site index is a measure of the potential growth of dominant or codominant canopy trees in each stand (Avery and Burkhart 2001). A site index value is given as the expected height at a standard or "base" age. Base age varies by productivity regions, smaller in more productive regions and higher base ages in less productive sites. Site indices are usually drawn as a series of curves to representing different site index values based on a variety in soil conditions and site characteristics the species may encounter across the habitat range. Site indices are operationally given as an equation such that one can predict site index from current age and height.

There exist two types of site index equation forms: base-age variant and base-age invariant. Base-age variance determines whether the shape of the growth curve can be altered with changes in the base age, or rotation length. Base-age invariant equation forms allow for flexibility in assessing curve shape while changing the maximum age of the individuals. Utilizing a base-age invariant equation allows the modeler to fit curves without having to know many parameters prior. Since hybrid poplar is a short-rotation tree species, changes in one or two years in base-age would have a large effect on the total rotation. Therefore, a base-age invariant model would be best suited for this species. Furthermore, the optimal financial or biological rotation age has yet to be established for hybrid poplar, especially in the upper Great Lakes region. A base-age invariant equation 
form is best suited for this site index model due the relatively short time span and unknown rotation for hybrid poplar.

Many forms of height prediction models exist, which are the basic roots of a site index model. Some forms include a difference equation approach, algebraic difference approach, segmented models, generalized algebraic difference approach, and mixed effects models (Burkhart and Tome 2012). Each form of the model gets slightly more complex and harder to apply. The difference approach takes advantage of a series of measurements on the same tree, allowing for the "difference" between time series. Segmented models allow for two different models to be applied to one series of curves. This allows for better flexibility if one model follows data better in early years and another in later years (Burkhart 2012). For example, with a data set of red pine trees in the Northern Great Lakes, Jones and Reed (1991) found a two-segment performed better than single monomolecular equation for differences in growth form between early and late years. Generalized algebraic difference approach allows the user to further personalize an algebraic difference approach, for example a direct asymptote can be entered if a maximum height is needed.

There exist many equations to model tree growth. Most well-known are Schumacher (1939) and Chapman-Richards (Pienaar and Turnbull 1973), among others (Clutter 1983). This analysis chose among the easiest to apply and most frequently used site index models. The Schumacher model is an adaptation of the Pearl-Reed equation (MacKinney et al. 1937), which had a drawback that required previous knowledge of maximum yield (Schumacher 1939). This new adapted Schumacher model, or modification of this basic model, is one of the most frequently used (Cao and Durand 1991, Clutter 1983, Allen II and Burkhart 2015). Recently Pszwaro et al. (2016) tried to use the Schumacher equation to model growth of red maple in Wisconsin and Michigan, but found the model did not exhibit enough flexibility to fit the dataset. The Schumacher equation was first introduced in 1939, and later adjusted by Clutter (1983) into the Schumacher difference form. This equation form is set to capture the year-to-year differences in height and age from trees with continuous remeasurement data. From the 
growth measurements modeling the yearly differences in height, a growth trend is observed.

The Bailey-Clutter (1974) is a base age invariant polymorphic model, which is now known as the algebraic difference approach (Burkhart 2012). The ChapmanRichards model is a modification of von Bertalanffy's growth model such that equation mirrors biological and physiological growth (Pienaar and Turnbull 1973).

Site index models have been created for hybrid poplar and aspen in Sweden by Johannson $(2011,2013)$. Site index curves have been produced for hybrid aspen by Johansson (2013) in Sweden for plantations up to 50 years old. The hybrid type is not known as plantations were established previously and landowners did not recollect the hybrid used (Johansson 2013). Although these site index models are for similar hybrid types, the top height models are not appropriate for use in our Hybrid Poplar Network or the Great Lakes region generally due to climatic differences.

A search of the literature yielded no hybrid poplar site index curves for the United States and no suitable replacement is available. Site index curves have been developed for many commercial tree species in the United States (Carmean et al. 1989) and there are specialized curves for short rotation species such as eastern cottonwood (Populus deltoides) from Cao and Durand (1991), but neither were implemented for use in these plantations. The short rotation eastern cottonwood is not an applicable surrogate due to the difference in geographic range. Furthermore, Cao and Durand (1991) eastern cottonwood site index model may not sufficient for application because growth pattern differences may exist within the same genus.

If hybrid poplars are to be accepted as an economically viable source of biomass for coal replacement, additional research needs to be conducted especially if this crop species is to be implemented at an operational scale. While economic viability is necessary for overall acceptance of hybrid poplar as a feedstock, there has yet to be a consensus on basic expected gains and growth for these hybrids.

The goal for this analysis was to develop a suite of hybrid poplar site index curves from the Michigan Technological University Hybrid Poplar Network annual growth data. Using these data, we tested base models from the site index models mentioned: 
Schumacher, Bailey and Clutter and Chapman-Richards. After a base model is selected the differences in experimental design for hybrid type, spacing, and stock type were also tested. From the developed model, region-specific site index curves for hybrid poplar should inform public and private landowners about the expected gains.

\subsection{Data \& Methods}

The Michigan Technological University Hybrid Poplar Network comprises 11 plantations across Ontonagon and Houghton counties in Western Upper Peninsula, and Cheboygan and Presque Isle counties in Northern Lower Peninsula of Michigan (Figure $1.1 \& 1.2)$. These plantations have individuals of two different hybrids, $P$. deltoides $x P$. nigra (DN34) and P. nigra $x$ P. maximowiczii (NM6), at three different tree spacing designs (3.3, 6.1, and $8.9 \mathrm{~m}^{2} /$ tree) and multiple tree stock types (cutting, rooted, and pole). To test statistical differences between experimental characteristics, plantations are set up in a grid of replicated blocks with two replications at each site. Data collected at these sites have continuous height and diameter recording each year starting at the year of establishment (Table 1.1). Plantations are found on a variety of soil types with slightly varied climatic conditions (Table 1.1).

Hybrid poplar plantations within the Network have a hierarchical form with treatment units varying on hybrid, spacing, and stock type within each plantation. At each plantation, the full representation of the treatment design is not replication, such that each plantation is not a perfect replication of another. For example, the $3.3 \mathrm{~m}^{2} /$ tree spacing is the only representation for that characteristic at Cowper plantation. Within each treatment unit not all individuals are sampled. To reduce to influence of edge effects due to increased sunlight on treatment unit edges, sampling occurred on an inner subset. For example, the outside 3 rows/columns within a $3.3 \mathrm{~m}^{2} /$ tree unit are not measured, leaving only the inside 6 rows and 6 columns ( 36 of 144 total trees are measured). Size of the treatment units were between $0.048-0.057$ ha, roughly $1 / 20$ ha. Treatment units are placed randomly within the plantation, reducing part of the hierarchical nature of the experiment. By measuring annually, autocorrelation is introduced into the dataset due to consecutive measurements being related. 


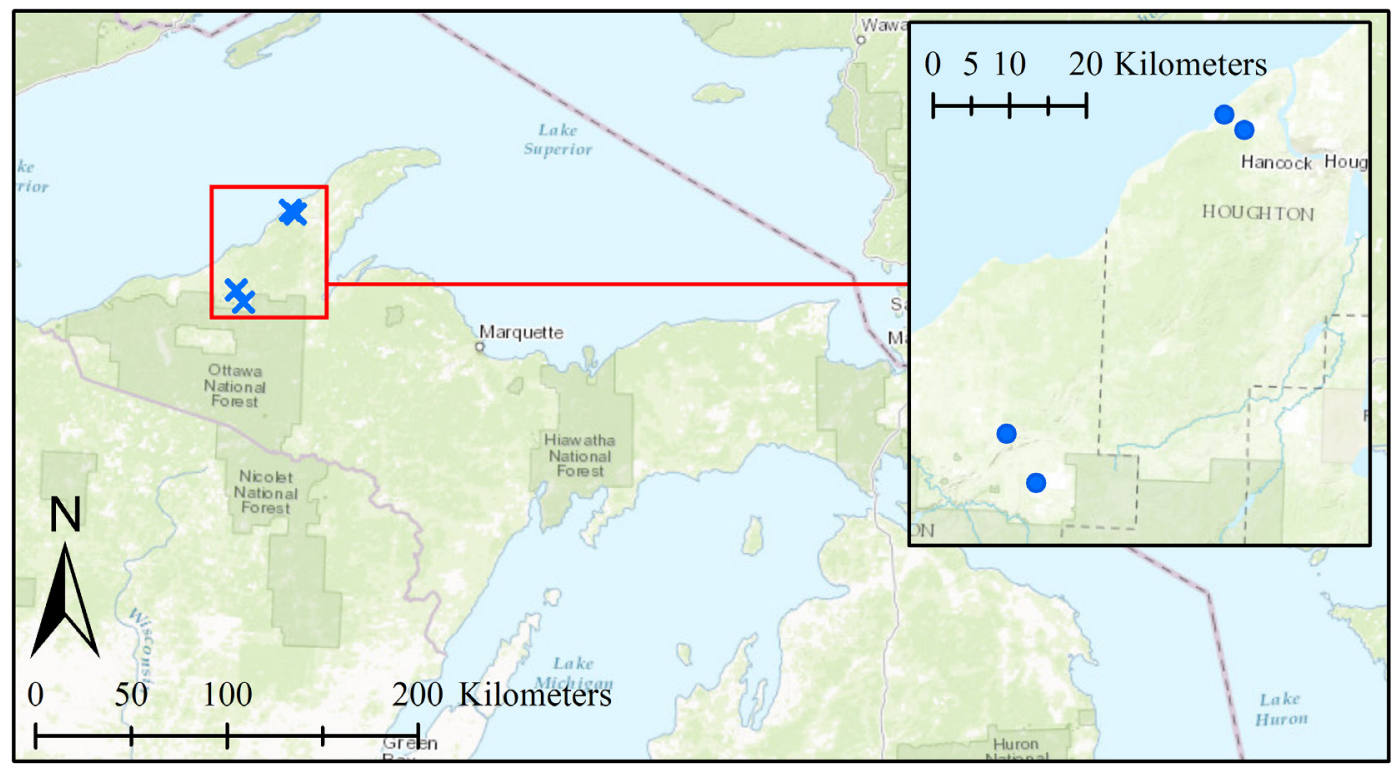

Figure 1.1. Location plantations within the Michigan Technological University Hybrid Poplar Network in the Upper Peninsula of Michigan, four plantations total. Copyright: (C) 2014 National Geographic Society, i-cubed. 


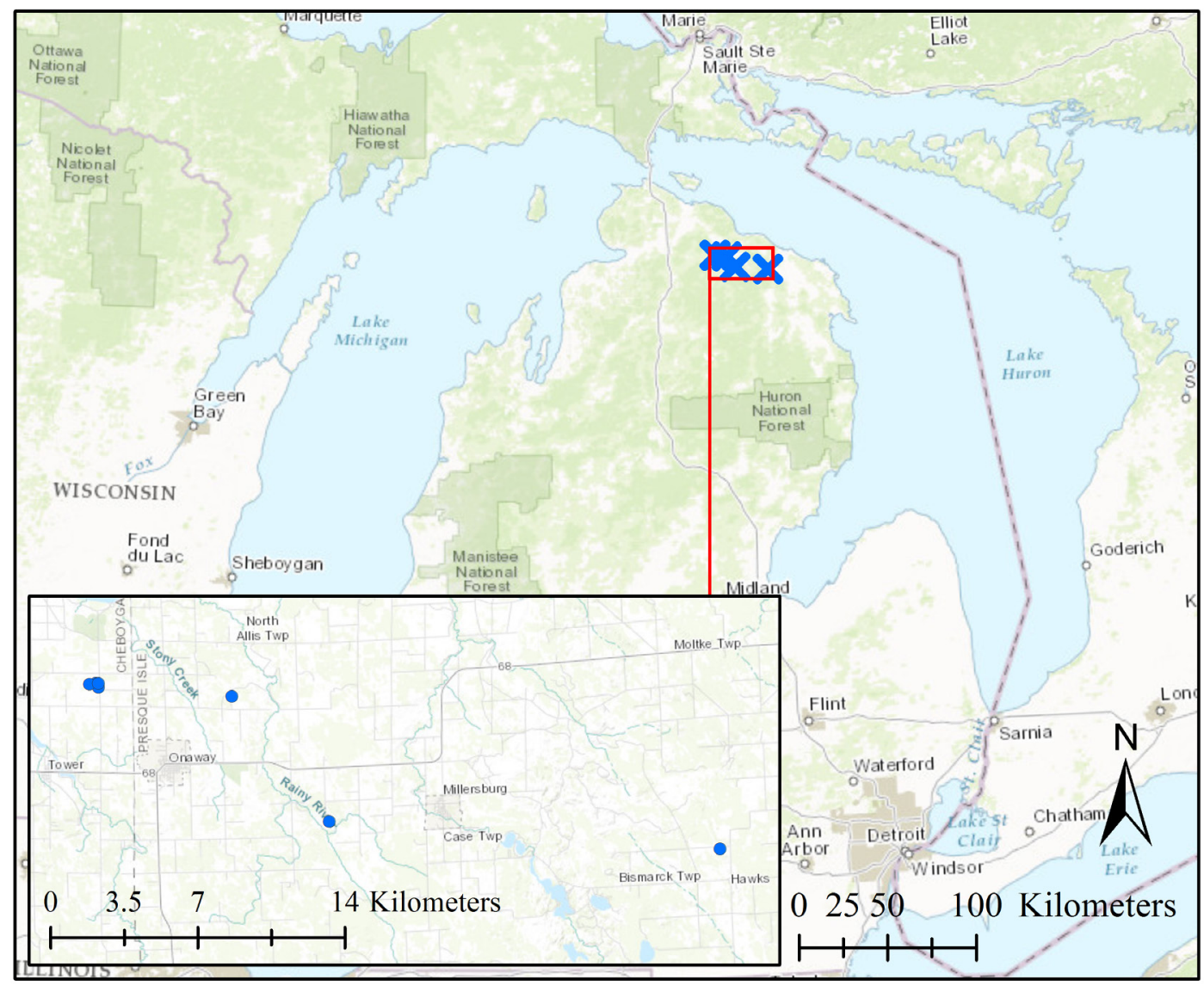

Figure 1.2. Location plantations within the Michigan Technological University Hybrid Poplar Network in the Lower Peninsula of Michigan, seven plantations total. Copyright: (C) 2014 National Geographic Society, i-cubed.

Table 1.1. Site descriptions for plantations in the Michigan Technological University Hybrid Poplar Network.

\begin{tabular}{|c|c|c|c|c|c|c|}
\hline Site Name & $\begin{array}{c}\text { Planting } \\
\text { Year }\end{array}$ & $\begin{array}{l}\text { Growing } \\
\text { Seasons }\end{array}$ & $\begin{array}{l}\text { Avg. } \\
\text { Precip. } \\
\text { inches }\end{array}$ & $\begin{array}{c}\text { Avg. } \\
\text { Max } \\
\text { Temp. } \\
{ }^{\circ} \mathrm{F}\end{array}$ & $\begin{array}{l}\text { Avg. } \\
\text { Min } \\
\text { Temp. } \\
{ }^{\circ} \mathrm{F}\end{array}$ & Soil \\
\hline
\end{tabular}

\section{Lower Peninsula}

\begin{tabular}{|c|c|c|c|c|c|c|}
\hline $\begin{array}{l}\text { LaHaie } \\
\text { Roadside }\end{array}$ & 2008 & 8 & 29 & 55 & 32 & Onaway loam \\
\hline $\begin{array}{c}\text { LaHaie } \\
\text { Backfield }\end{array}$ & 2008 & 8 & 29 & 55 & 32 & $\begin{array}{l}\text { Fairport fine sandy } \\
\text { loam/Bonduel loamy } \\
\text { very fine sand }\end{array}$ \\
\hline
\end{tabular}




\begin{tabular}{|c|c|c|c|c|c|c|}
\hline Robbins & 2008 & 8 & 29 & 55 & 32 & $\begin{array}{l}\text { Krakow flaggy fine } \\
\text { sandy loam }\end{array}$ \\
\hline Cowper & 2009 & 7 & 29 & 55 & 32 & Onaway loam \\
\hline Thompson & 2010 & 6 & 29 & 55 & 33 & $\begin{array}{l}\text { Melita loamy } \\
\text { sand/Rubicon } \\
\text { sand/Emmet sandy } \\
\text { loam } \\
\text { Cheboygan loamy } \\
\text { sand/Detour flaggy } \\
\text { loam/Emmet sandy } \\
\text { loam } \\
\text { Charity fine sandy }\end{array}$ \\
\hline LaHaie New & 2012 & 4 & 29 & 55 & 32 & $\begin{array}{l}\text { loam/Emmet sandy } \\
\text { loam }\end{array}$ \\
\hline \multicolumn{7}{|l|}{ Upper Peninsula } \\
\hline Truscott & 2011 & 5 & 32 & 51 & 30 & $\begin{array}{l}\text { Loggerhead-Big } \\
\text { Irong-Belding } \\
\text { complex }\end{array}$ \\
\hline Puuri & 2011 & 5 & 29 & 51 & 33 & $\begin{array}{l}\text { Keweenaw-Kalkaska } \\
\text { complex }\end{array}$ \\
\hline Miller & 2012 & 4 & 28 & 51 & 32 & $\begin{array}{l}\text { Munising-Yalmer } \\
\text { complex }\end{array}$ \\
\hline Lukkari & 2012 & 4 & 32 & 51 & 30 & $\begin{array}{l}\text { Algonquin silty } \\
\text { clay/Negwegon silty } \\
\text { clay }\end{array}$ \\
\hline
\end{tabular}

Tree measurements were recorded on the Michigan Technological University Hybrid Poplar Network during the fall or spring seasons, prior or after growing season. Height was measured in meters with a height pole, if applicable, or hypsometer when individuals became too tall (Laser Technology, Inc., Centennial, Colorado). Diameter at breast height $(\mathrm{DBH})$ was recorded with a digital caliper or diameter tape.

The three stock types used in plantations were cutting, rooted, or pole, and have major differences in height at planting. These differences in height at time of planting are attributed to varying lengths of growth and height achieved at the nursery. For example, the cutting stock type is a new shoot cut and placed into the ground within one year, rooted and pole stock were grown in the ground one year then removed from the stool bed to be sold. The differences in rooted and pole stock are merely just height differences. Pole stock is considered "large" that year of growth and rooted is "medium" growth, therefore it is relatively subjective to the nursery worker. To account for growth 
differences in stock type the planting height for each tree was subtracted from all height measurements, therefore only measuring the growth achieved while in the new plantation. After planting height was subtracted from total height, negative growth values occurred if the tree experienced dieback. When this happened, it was changed to zero. Subtracting the planting height removes all bias from yearly changes in stock type size as well, for example, the average planting height for pole stock in 2010 is almost $50 \%$ larger than 2009 (Table 1.2). Since all individuals are genetically identical, no one stock type has growth superiority once planting height is subtracted. Accounting for the planting height removed any bias created from favorable nursery stock or lingering effects from nursery site conditions.

Table 1.2. Average planting height for each stock type across all years planting occurred across the Michigan Technological University Hybrid Poplar Network.

\begin{tabular}{ccc}
\hline $\begin{array}{c}\text { Planted } \\
\text { Year }\end{array}$ & Stock Type & $\begin{array}{c}\text { Avg Planted } \\
\text { Height } \\
\text { (meters) }\end{array}$ \\
\hline 2007 & pole & 1.25 \\
2008 & pole & 1.37 \\
2009 & pole & 1.26 \\
2010 & pole & 1.86 \\
2007 & rooted & 0.60 \\
2008 & rooted & 0.58 \\
2009 & rooted & 0.68 \\
2010 & rooted & 0.77 \\
2007 & cutting & 0.02 \\
2008 & cutting & 0.03 \\
2009 & cutting & - \\
2010 & cutting & - \\
2011 & cutting & 0.10 \\
2012 & cutting & 0.33 \\
\hline
\end{tabular}

For modeling purposes this total age was used instead of other metrics such as breast height age, since time to achieve breast height is variable across sites. Total age was chosen for our analysis since year of planting is known and easier to obtain, furthermore, total age is generally more practical in plantation-type settings (Perin et al. 
2013). Use of breast-height age has advantages such as reduction of variability due to confounding factors such as poor weed control or shock of transplanting early in plantation establishment, but it is much more difficult to assess for each plantation. In circumstances where total age or year of plantation establishment and stock type is not known, coring at the base of a tree to find total age requires little effort.

From this database, dominant trees for each plantation are identified by creating a subset of five trees from each treatment unit to model site index. These dominant trees were determined based on total height achieved after the most recent, 2015, growth year. A synthesis of number of observations can be found in Table 1.3. From each treatment unit $(\sim 1 / 20 \mathrm{ha})$ the tallest five trees were selected, which would equate to the industry standard of tallest 100 trees per hectare.

Table 1.3. Number of observations for dominant individuals in each hybrid, spacing, and stock type.

\begin{tabular}{|c|c|c|c|c|c|c|c|}
\hline \multicolumn{3}{|r|}{ NM6 } & \multicolumn{5}{|c|}{ DN34 } \\
\hline \multirow[b]{2}{*}{ Stock Type } & \multicolumn{5}{|c|}{ Spacing $\left(\mathrm{m}^{2} /\right.$ tree $)$} & \multirow[b]{2}{*}{8.9} & \multirow[b]{2}{*}{ Total } \\
\hline & 3.3 & 6.1 & 8.9 & 3.3 & 6.1 & & \\
\hline pole & 201 & 5 & 0 & 155 & 40 & 0 & 401 \\
\hline rooted & 714 & 318 & 207 & 616 & 504 & 189 & 2548 \\
\hline cutting & 1186 & 229 & 31 & 1048 & 0 & 0 & 2494 \\
\hline
\end{tabular}

\subsubsection{Base Model Development}

All dominant trees were used to compare and select the base model form for further analyses. During base model development differences in experimental factors are not being tested, therefore all individuals were treated alike. To attribute for the lack of older sites, the top height and age for each tree was used as the maximum achievable height for that specific tree. This method has been previous utilized by Cao and Durand (1991). For example, if we have a 5-year-old tree and the tallest height in those 5 years was 3.5 meters, then that tree has a 5-year rotation length with maximum height achieved 3.5 meters, therefore each tree has a distinct modeled rotation. This pooled dataset 
retained all characteristics of statistical importance for use later in the non-linear mixed effects model. There are 5443 observations of dominant individuals across all plantations, and 895 individuals make up the dominant tree dataset.

Cao (1993) assessed differences in equation formats and the ability of each to model growth data, therefore this research was utilized as a starting point for base model selection. Cao (1993) tested standard forms of the Schumacher (1939), ChapmanRichards, Bailey and Clutter (1974), as well as other differential equations (Cao, 1993). From Cao (1993) it was determined that Schumacher 1b, Schumacher 1c, ChapmanRichards 2c, and the Bailey and Clutter 3c equation forms were the focus of our base model options. For all equations: $\mathrm{S}$ is site index, $\mathrm{H}_{1}$ is current height, $\mathrm{A}_{1}$ is current height, and $\mathrm{A}_{2}$ is rotation age or predicted age.

A generalized version of the Schumacher equation (1) used is as follows: $\ln (S)=\ln \left(H_{1}\right)+\beta_{1}\left(\frac{1}{A_{2}}-\frac{1}{A_{1}}\right)($ Equation 1.1)

$\mathrm{S}$, site index, is the predicted height at for the age at $\mathrm{A}_{2}$ years. The prediction for height is a measure of the reciprocal of age difference added to the previous year's height $\mathrm{H}_{1}$. By performing transformations on the $\mathrm{x}$ and $\mathrm{y}$ variables, it allows a simple linear regression to be calculated. The predictor variable for this analysis is the difference of reciprocal ages $\left(\mathrm{X}=\left(\frac{1}{A_{2}}-\frac{1}{A_{1}}\right)\right)$, and the response variable is the difference of natural $\log$ of tree heights $\left(\mathrm{Y}=\ln \left(H_{2}\right)-\ln \left(H_{1}\right)\right)$. Once these are established a zero-intercept linear regression can be applied to determine the curve of growth.

With equation 1.1 the response variable is the natural $\log$ of site index. As described by Cao (1993) this method can be difficult to rationalize since it is not reported in "normal" terms. Cao (1993) proposed an alternative method to model Schumacher's growth curve, which he refers to as method $1 \mathrm{c}$, listed here as Equation 1.2): $S=H_{1} \exp ^{b_{2}\left(\frac{1}{A_{2}}-\frac{1}{A_{1}}\right)}$ (Equation 1.2)

The third model used for analysis is Bailey \& Clutter (1974) base-age invariant polymorphic site index curve. Using method $\mathrm{c}$ for model fitting, the follow equation is used: 
$S=\exp \left(b_{1}+\left(\ln \left(H_{1}\right)-b_{1}\right)\left(\frac{A_{2}}{A_{1}}\right)^{b_{3}}\right)($ Equation 1.3)

Finally, the last model analyzed is the Chapman-Richards. Multiple forms of this Chapman-Richards model were analyzed by Cao (1993) for efficacy in fitting for site index. The model form presented in equation 1.4 is $2 \mathrm{c}$, which was deemed the most appropriate model version by Cao (1993).

$H_{1}=S\left(\frac{1-e^{b_{1} A_{2}}}{1-e^{b_{1} A_{1}}}\right)^{b_{2}}$ (Equation 1.4)

Statistical analyses on these four models were completed in the R Environment ( R Core Team 2015). All models were fit with a zero-intercept, with all curves initiating at the origin, as appropriate to represent the natural growth of trees from seedling establishment. Since we do not have sites that have reached the assumed base age of hybrid poplar (10 years), the max height and max age were assumed to be the greatest height and age achieved by each five top trees in each treatment unit.

To test the fit ability of the base equations presented, residual and QQ plots were created. Along with residual and QQ plots, we assessed equation fit using three additional fit statistics - mean difference, mean absolute difference, and root mean square error (RMSE). Once computed, the site index models were then ranked.

\subsubsection{Nonlinear Modeling}

Once the base equation and model is selected, a nonlinear mixed effect model was developed using top height data. The use of a nonlinear mixed effect model was chosen due to the inherent nature of data from remeasurement plots, this includes autocorrelation and heteroscedasticity from annual height measurements. The nonlinear model was constructed to constrain the ordered appearance of the experimental design, for example tree characteristics within treatment units and treatment units within sites. Previous work with nonlinear mixed effects models in loblolly pine by Anton-Fernandez (2011), chose to have a greater number of random effects to include variation from measurement year. This analysis did not include this additional layer of random effects to allow for some residual error within the model. If variation from measurement year was also included in 
the model as a random effect, there would be no randomness within the model to account for variance.

Random effects are modeled as follows:

For each $i$ th tree on the $j$ th treatment unit within the $k$ th site is as follows:

$$
\begin{gathered}
S=\exp \left(\alpha_{1 i j k}+\left(\ln \left(H_{1}\right)-\alpha_{1 i j k}\right)\left(\frac{A_{2}}{A_{1}}\right)^{\alpha_{3 i j k}}\right)(\text { Equation 1.5) } \\
\alpha_{1 i j k}=\gamma+b_{1 i}+b_{1 i j k} \\
\alpha_{3 i j k}=\beta+b_{3 i}+b_{3 i j k}
\end{gathered}
$$

Where $\mathrm{S}$ is site index, $\mathrm{H}_{1}$ is current height, $\mathrm{A}_{1}$ is current height, and $\mathrm{A}_{2}$ is rotation age or predicted age. The non-linear mixed effects model was developed using the nlme package in R (Pinheiro et al. 2012). Additional categorical variables for hybrid type, spacing, and stock type were added as fixed effects in a step-wise forward manner. The addition of fixed effects was tested using a likelihood ratio test (LRT), Akaike Information Criterion (AIC), and RMSE. An alpha value of 0.05 was used where applicable.

\subsection{Results}

\subsubsection{Base Model Analysis}

Both Schumacher $1 \mathrm{~b}$ and $1 \mathrm{c}$ are predicting yield at higher values than observed (points are plotting below the prediction line), showing a lack of fit (Figure 1.3).

Chapman-Richards predicts tree growth as a constant increase of height, showing a linear growth pattern (Figure 1.3). Finally, the Bailey \& Clutter model under predicts height in the first year post planting, but accurately predicts observed yield across years for which data is available. A summary of coefficients for each base model can be found in Table 1.4 . 


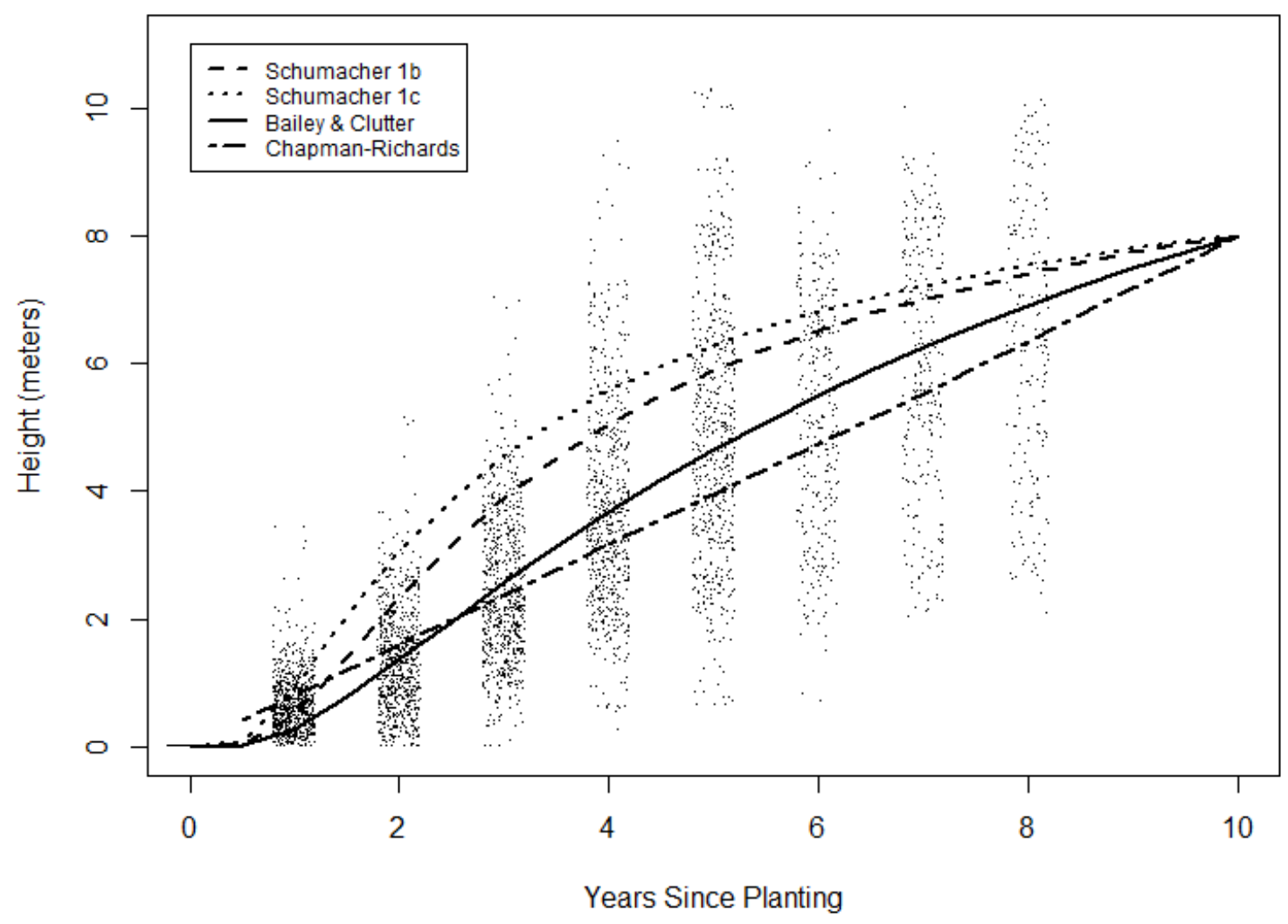

Figure 1.3. Base model curve shape for four models tested with height observations of dominant trees within each treatment unit. Site index value shown is 8 meters at 10 -years post-planting.

Table 1.4. Coefficients for fitted equations $1.1-1.4$.

\begin{tabular}{lccc}
\hline & $\mathrm{b}_{1}$ & $\mathrm{~b}_{2}$ & $\mathrm{~b}_{3}$ \\
\hline Schumacher 1b & -2.98 & & \\
Schumacher 1c & -2.422 & & \\
Bailey \& Clutter & 3.249 & & -0.576 \\
Chapman-Richards & 0.012 & 0.943 & \\
\hline
\end{tabular}

Residuals from these models were plotted for independence and normal distribution using base package in R (Figure 1.4). The Schumacher models both show a trend of early positive residuals, indicating the models may be predicting height greater than observed at young ages and under predicting later (Figure 1.4 a,b). Residuals from the Bailey-Clutter model appear to be the most centered on zero across all fitted values (Figure $1.4 \mathrm{c}$ ). 

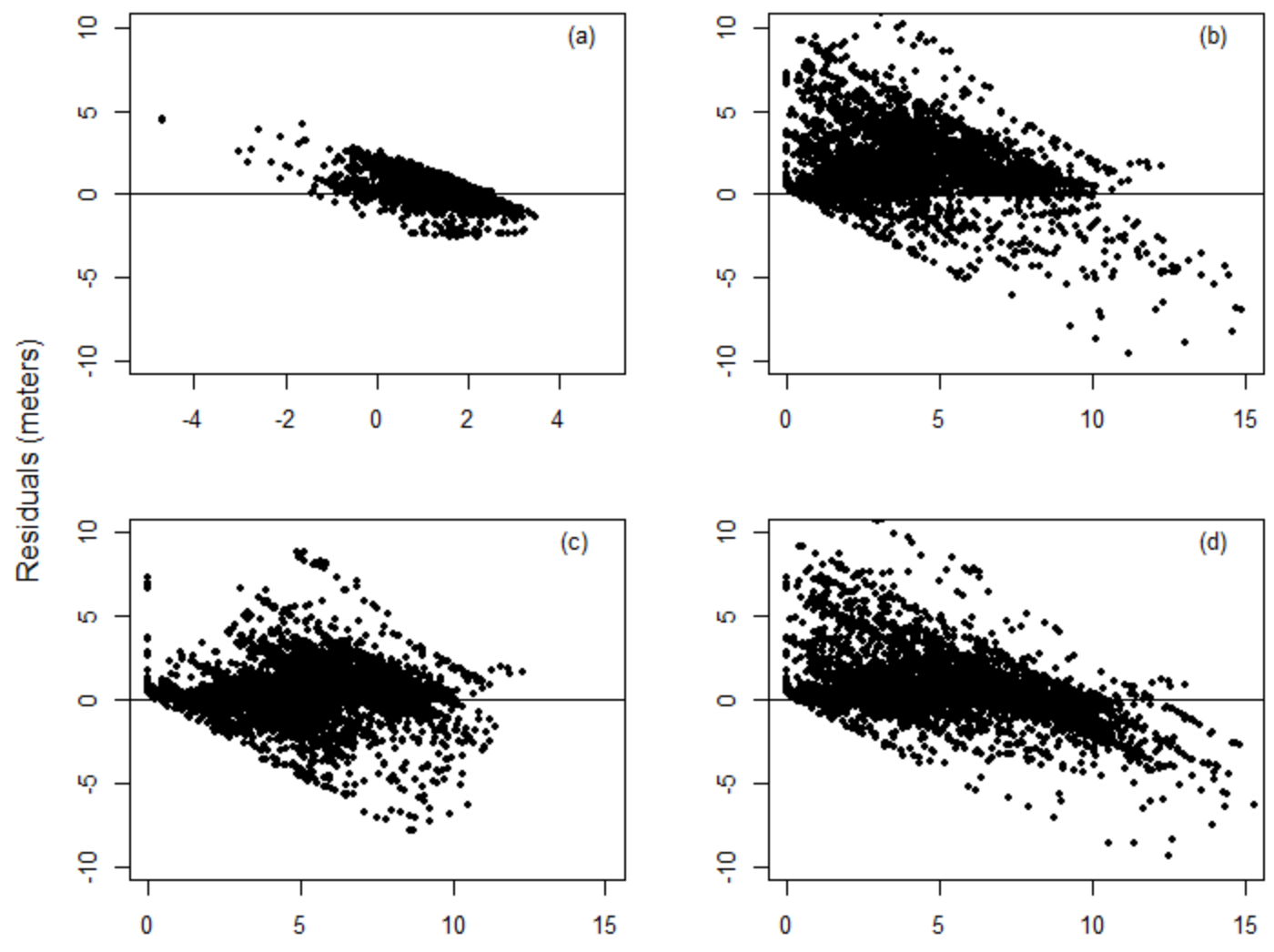

Fitted Values (years)

Figure 1.4. Residual plots for (a) Schumacher $1 \mathrm{~b}$ (shown as fitted $\ln (\mathrm{S})$ vs. residual $\ln (\mathrm{S})$ ), (b) Schumacher 1c, (c) Bailey \& Clutter, and (d) Chapman-Richards. 

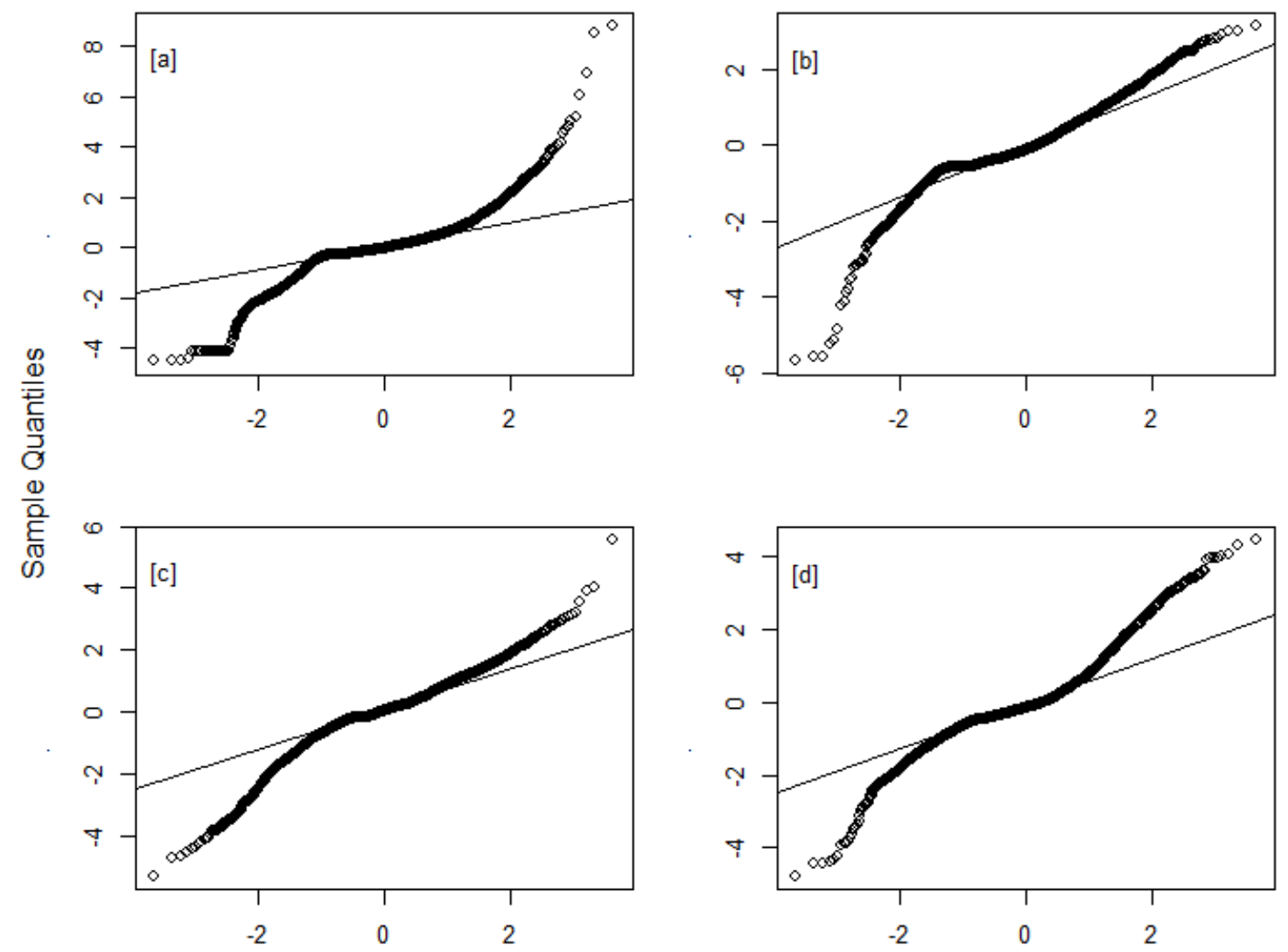

Theoretical Quantiles

Figure 1.5. Quantile-quantile (QQ) plot for (a) Schumacher 1b, (b) Schumacher 1c, (c) Bailey \& Clutter, and (d) Chapman-Richards.

A QQ (Quantile-Quantile) plot was created for each model using base package in $\mathrm{R}$ (Figure 1.5). Both forms of the Schumacher model appear to have issues with heavy tails (Figure $1.5 \mathrm{a}, \mathrm{b}$ ). The Bailey \& Clutter appears to be the most normally distributed (Figure $1.5 \mathrm{c}$ ). Along with the residual and QQ plots, evaluations statistics of RMSE, mean absolute difference, and mean difference were calculated and summarized in Table 1.5. The Bailey - Clutter model had the best rank for all evaluations and was selected as the base model of choice. 
Table 1.5. Evaluation statistics for the four site index base models tested.

\begin{tabular}{lcccc}
\hline Model & $\begin{array}{c}\text { Root Mean } \\
\text { Square } \\
\text { Error }\end{array}$ & $\begin{array}{c}\text { Mean } \\
\text { Absolute } \\
\text { Difference }\end{array}$ & $\begin{array}{c}\text { Mean } \\
\text { Difference }\end{array}$ & $\begin{array}{c}\text { Sum of } \\
\text { Ranks }\end{array}$ \\
\hline Schumacher 1b & 1.89 & 1.47 & 1.47 & 9 \\
Schumacher 1c & 2.65 & 1.74 & 1.36 & 11 \\
Bailey \& Clutter & 1.65 & 1.06 & 0.30 & 3 \\
Chapman - Richards & 2.08 & 1.23 & 0.49 & 7 \\
\hline
\end{tabular}

\subsubsection{Application of Nonlinear Model}

With the base model selection, random effects were added to the dataset by grouping data by tree, treatment unit, and site, and modeled by nonlinear mixed effects. This model without any fixed effects from tree characteristics is called the "generalized" model. The generalized model accurately reflects tree growth within Hybrid Poplar Network. By letting the left side of the equation vary to represent different site index values, a suite of curves is created (Figure 1.6). Site index values across the Network seem to be within the range of 4-12 meters at 10 years (Figure 1.6). 


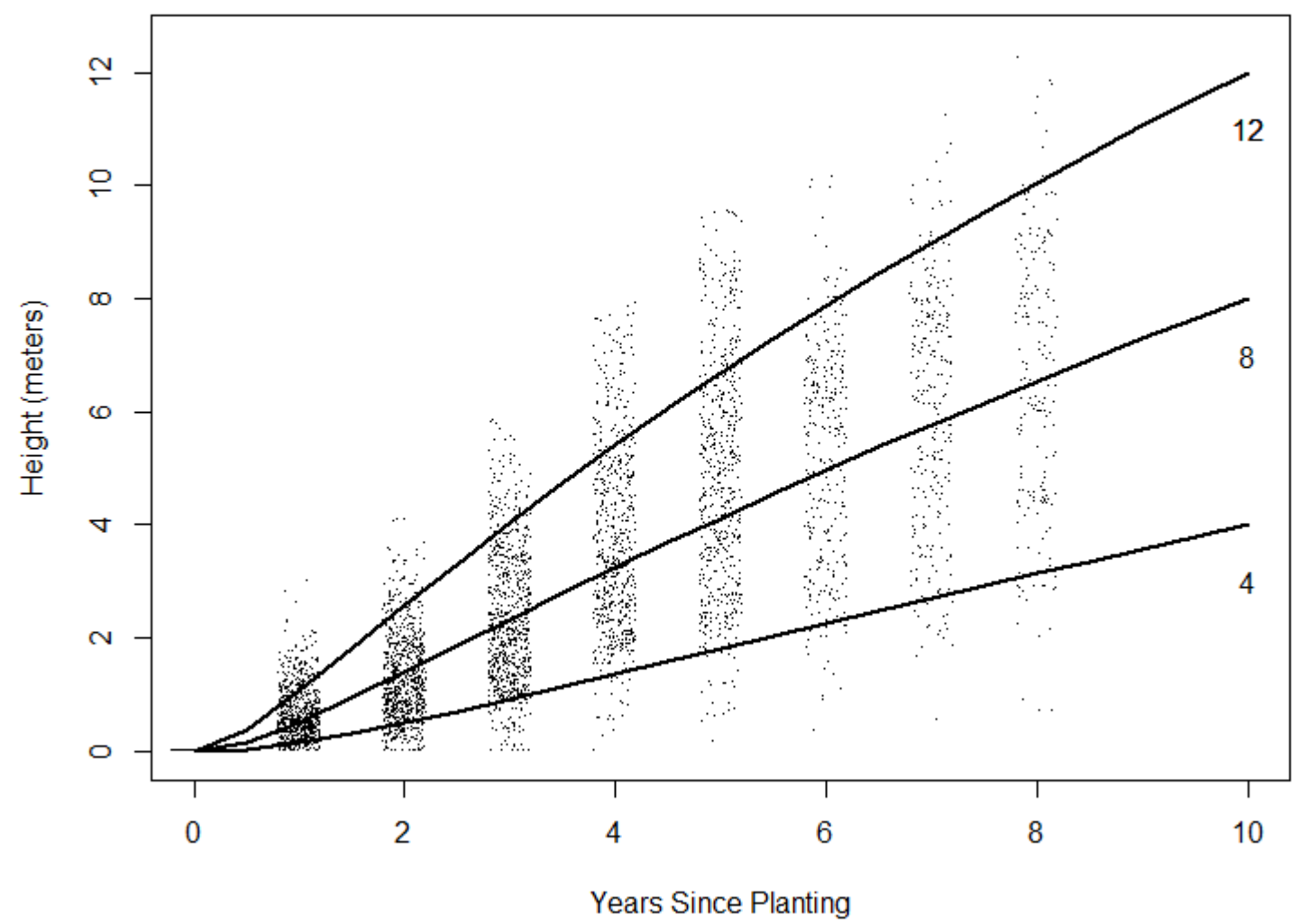

Figure 1.6. Generalized site index curves (12, 8, and 4 meters at 10 years) for Michigan Technological University Hybrid Poplar Network plotted with dominant trees.

The categorical variable for hybrid was added to the generalized model. A statistical difference in site index curve shape was not noted between the generalized model and the model including categorical variable for hybrid (LRT, $\mathrm{p}=0.4399)$ (Figure 1.7). Significant overlap of points between the two hybrid types further shows the insignificance of using hybrid as a predictor variable for site index curves (Figure 1.8). Planting density was tested against the generalized model and found not significant (LRT, $\mathrm{p}=0.9893$ ) (Figure 1.9). Overlap between planting densities of $6.1 \mathrm{~m}^{2} /$ tree and 8.9 $\mathrm{m}^{2} /$ tree further show non-significance (Figure 1.9). Viewing the raw data this further shows that $6.1 \mathrm{~m}^{2} /$ tree and $8.9 \mathrm{~m}^{2} /$ tree have significant overlap between range of data available (Figure 1.10). 


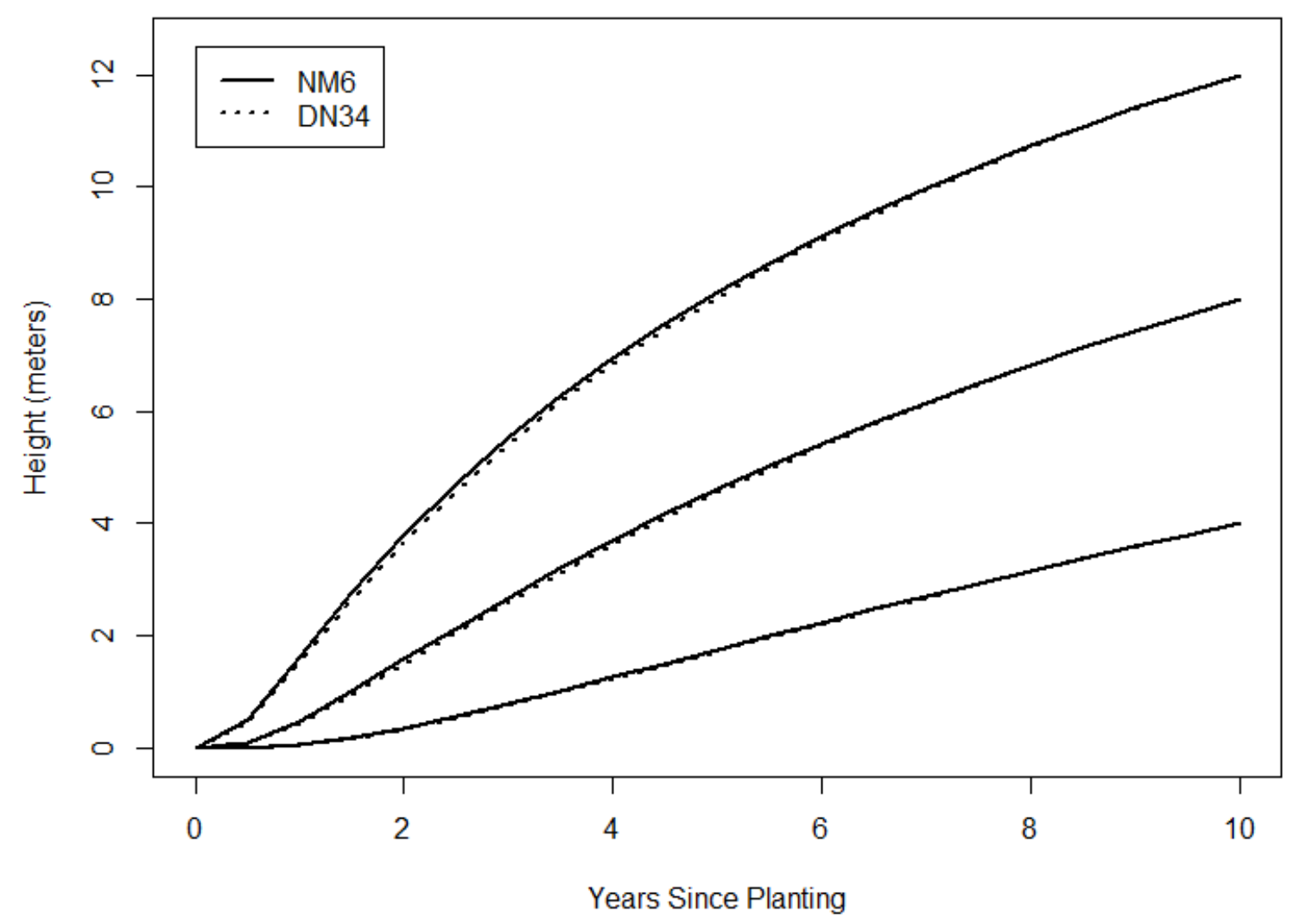

Figure 1.7. Site index curves $(12,8$, and 4 meters at 10 years) for two hybrid types in Michigan Technological University Hybrid Poplar Network. 


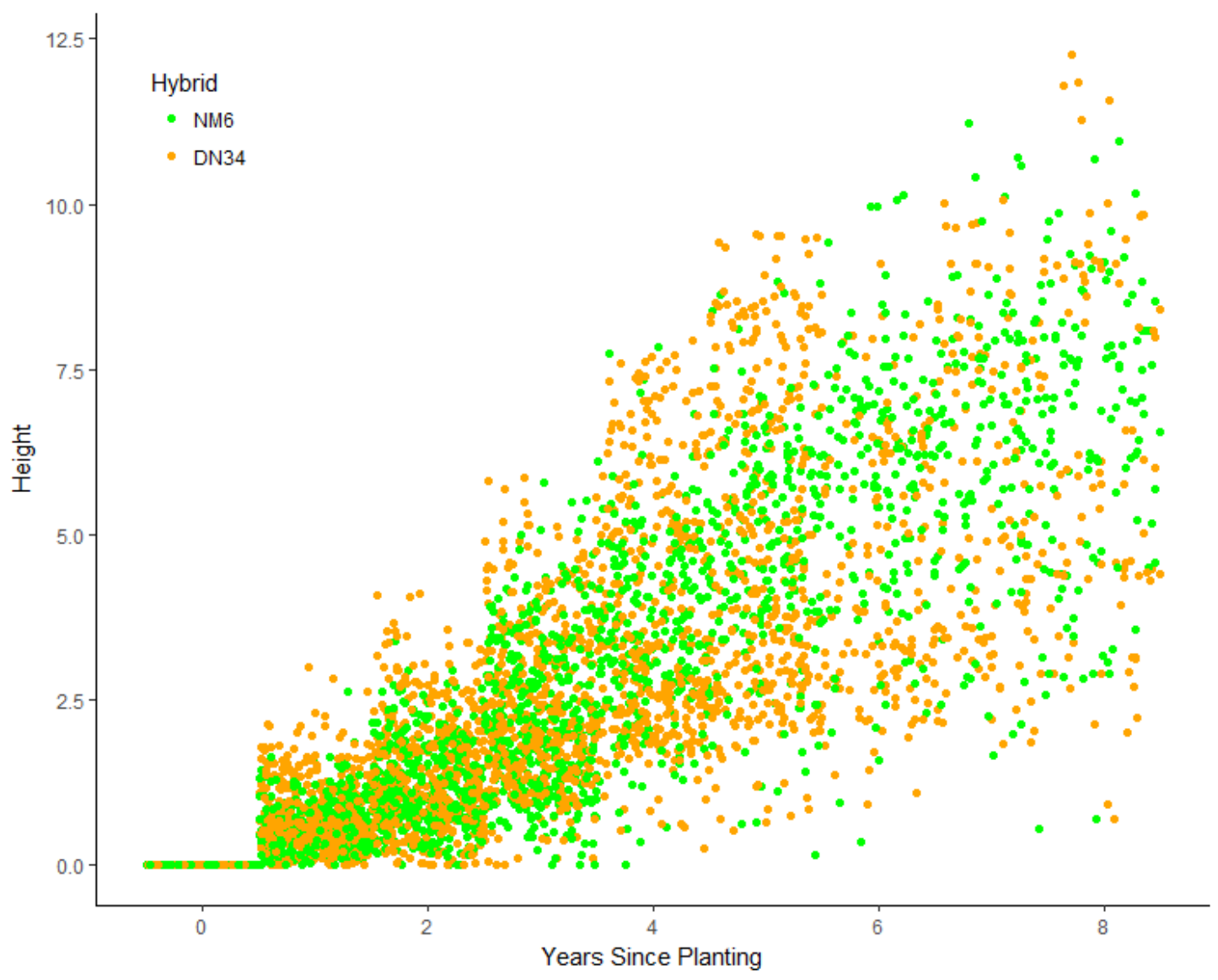

Figure 1.8. Height values for hybrid types of NM6 and DN34 within the Michigan Technological University Hybrid Poplar Network. 


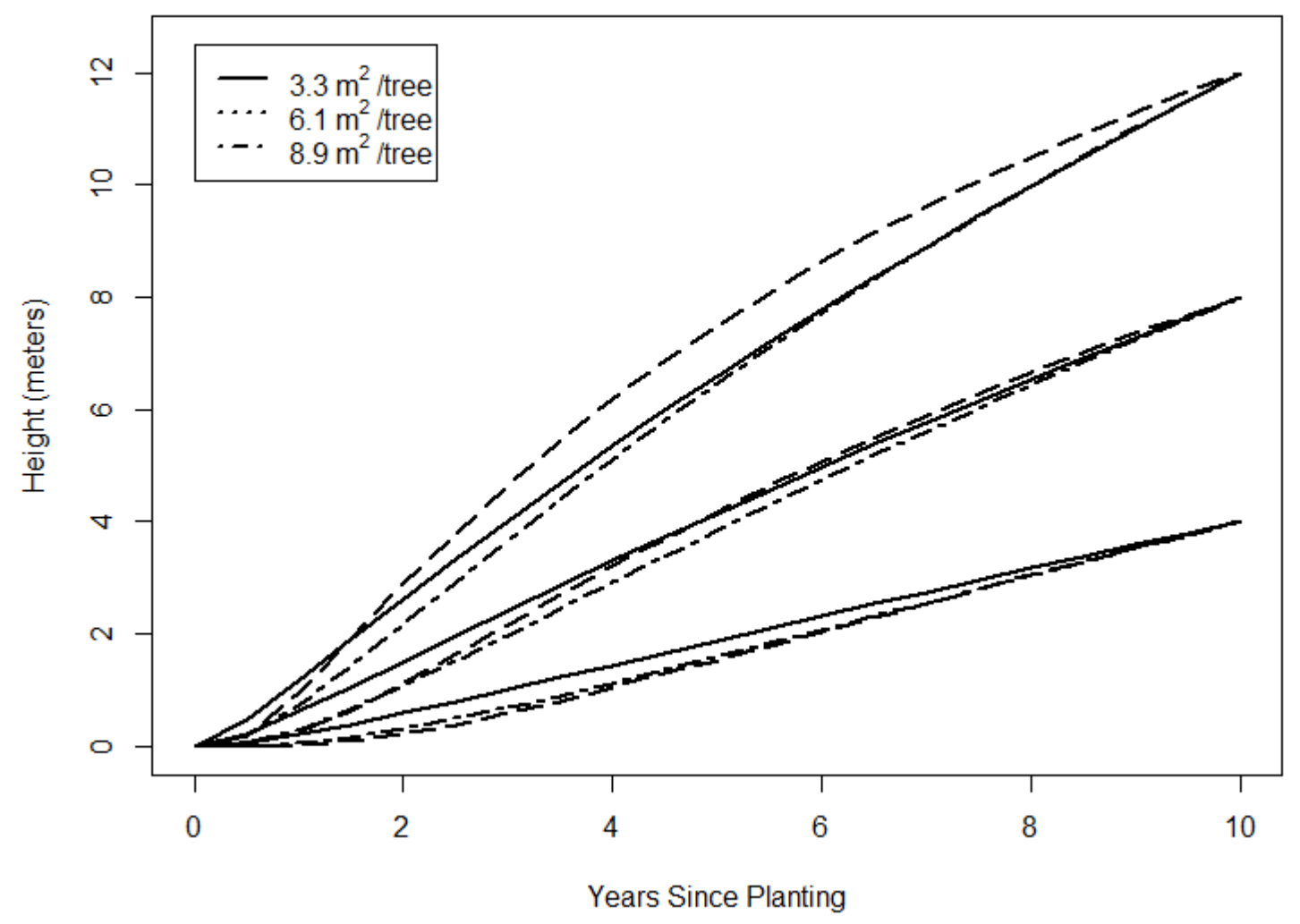

Figure 1.9. Site index curves $(12,8$, and 4 meters at 10 years) for Michigan Technological University Hybrid Poplar Network at three different planting densities. 


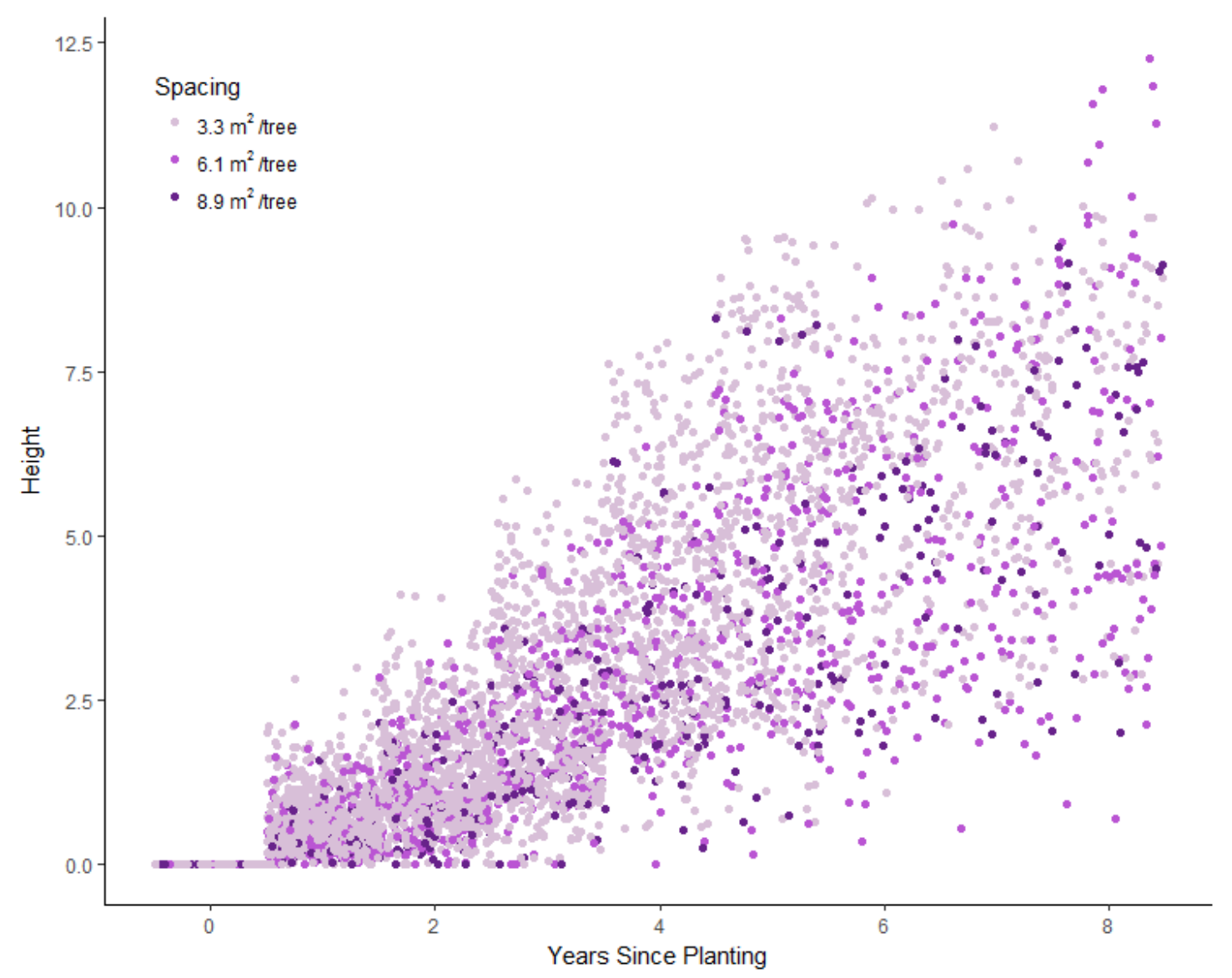

Figure 1.10. Height values for treatment unit densities of $3.3,6.1$, and $8.9 \mathrm{~m} 2 /$ tree within the Michigan Technological University Hybrid Poplar Network.

A statistical difference was seen when stock type was included to the generalized model (LRT, $\mathrm{p}<0.0001$ ). Significance in stock types shows that the pattern of growth is different for rooted-, cutting-, or pole-origin trees (Figure 1.11). In lower site index values, pole and rooted stock show a slower growth form that the cutting stock type. To further extract the reason why stock type was significant, the data was plotted to see if a trend could be synthesized (Figure 1.12). Pole and rooted stock (red and blue dots) show the greatest variability in height observations across all plantations (Figure 1.12). Cutting stock type is not well represented past 5 years post planting (Figure 1.12). 


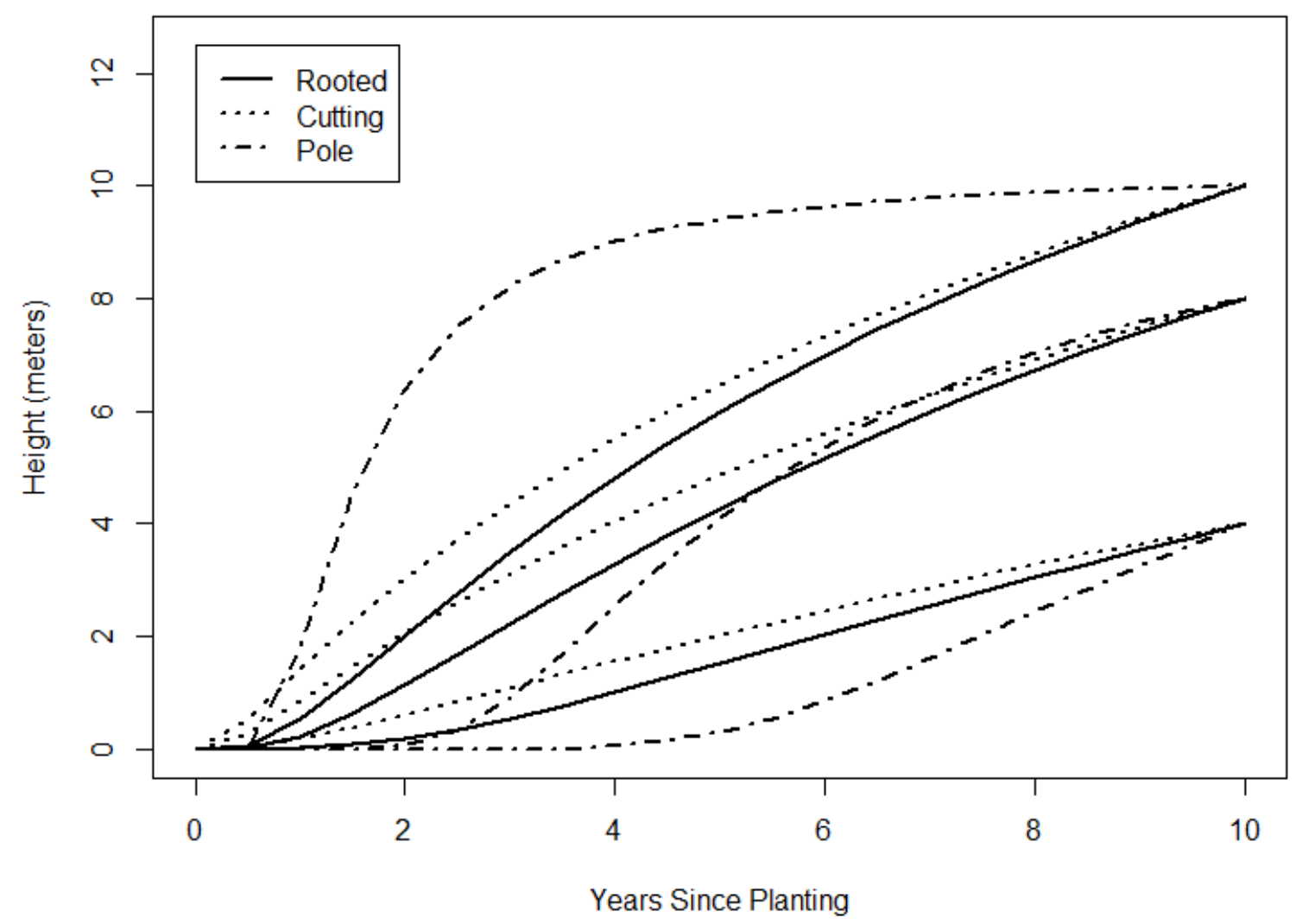

Figure 1.11. Site index curves (10,8, and 4 meters at 10 years) for Michigan Technological University Hybrid Poplar Network for three different stock types. 


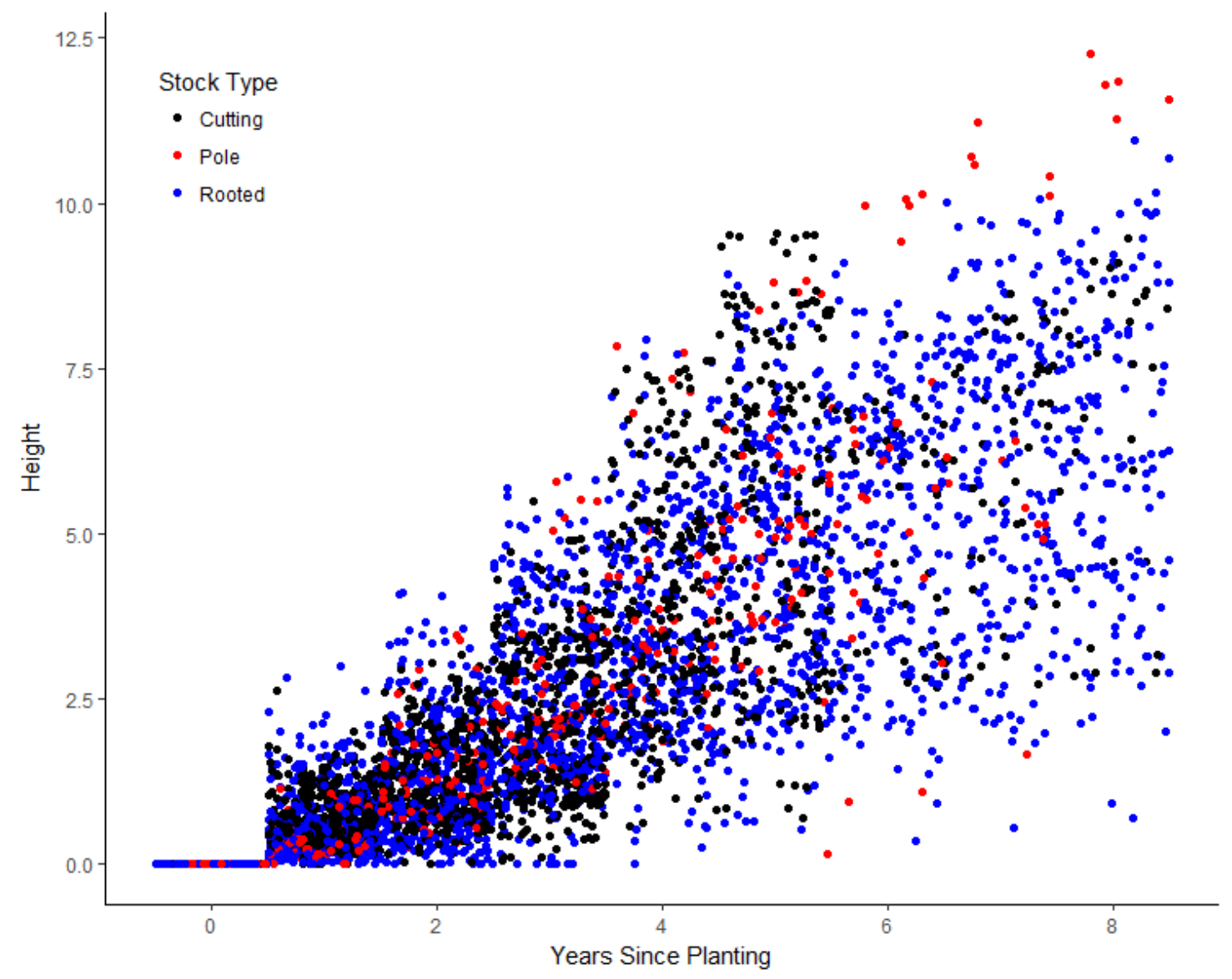

Figure 1.12. Height values for cutting, pole, and rooted stock types for Michigan Technological University Hybrid Poplar Network.

Stock type was the only significant categorical variable; therefore, hybrid and spacing are added to this model to test for increased accuracy. The addition of hybrid was an improvement over the stock type only model (hybrid + stock type vs. stock type) (Table 1.6). Spacing, or planting density, was also an improvement over the stock type only model (Table 1.6). The test for hybrid + spacing was not included in analysis because neither variable was significant separately. Finally, including all categorical variables was statistically significant over hybrid + stock type and spacing + stock type (LRT, $\mathrm{p}<0.0001)$.

The model including all three categorical variables is deemed statistically significant from a likelihood ratio test, but has a higher AIC value than the spacing + stock type model. This shows that even though adding all the variables is significant, it 
does not provide any additional meaningful results. Therefore, the spacing + stock type model would explain most variance without addition of extraneous variables.

Table 1.6. Summary of step-wise forward nonlinear mixed effects model analysis.

\begin{tabular}{lcccc}
\hline \multicolumn{1}{c}{ Model } & RMSE & AIC & \multicolumn{2}{c}{ LRT p-value } \\
\hline generalized & 1.739 & 12,049 & - & \\
hybrid & 1.740 & 12,055 & 0.4399 & \\
spacing & 1.735 & 12,057 & 0.9893 & \\
stock type & 1.748 & 11,966 & $<0.0001$ & \\
hybrid + stock type & 1.586 & 10,965 & $<0.0001$ & $\#$ \\
spacing + stock type & 1.586 & 10,672 & $<0.0001$ & $\# \#$ \\
hybrid + spacing + stock type & 1.585 & 10,700 & $<0.0001$ & $\# \#$ \\
\hline
\end{tabular}

\# tested over spacing, stock type models

\#\# tested over spacing, stock type models

\#\#\# tested against hybrid + stock type and spacing + stock type

NOTE: hybrid + spacing not tested since hybrid and spacing were not significant separately.

For the generalized model the value of coefficient b1 is 5.544 (SE 0.128) and b3 is -0.253 (SE 0.014), which can be incorporated into Equation 1.5 to produce Figure 1.6. Comparison of the generalized nonlinear model to previous site index models for species within the same genus are presented in Figure 1.13 curve for 8 meters at 10 years post planting is represented. Both Cao and Durand (1991) and Johansson (2011) under predict height for individuals up to age seven (Figure 1.13) 


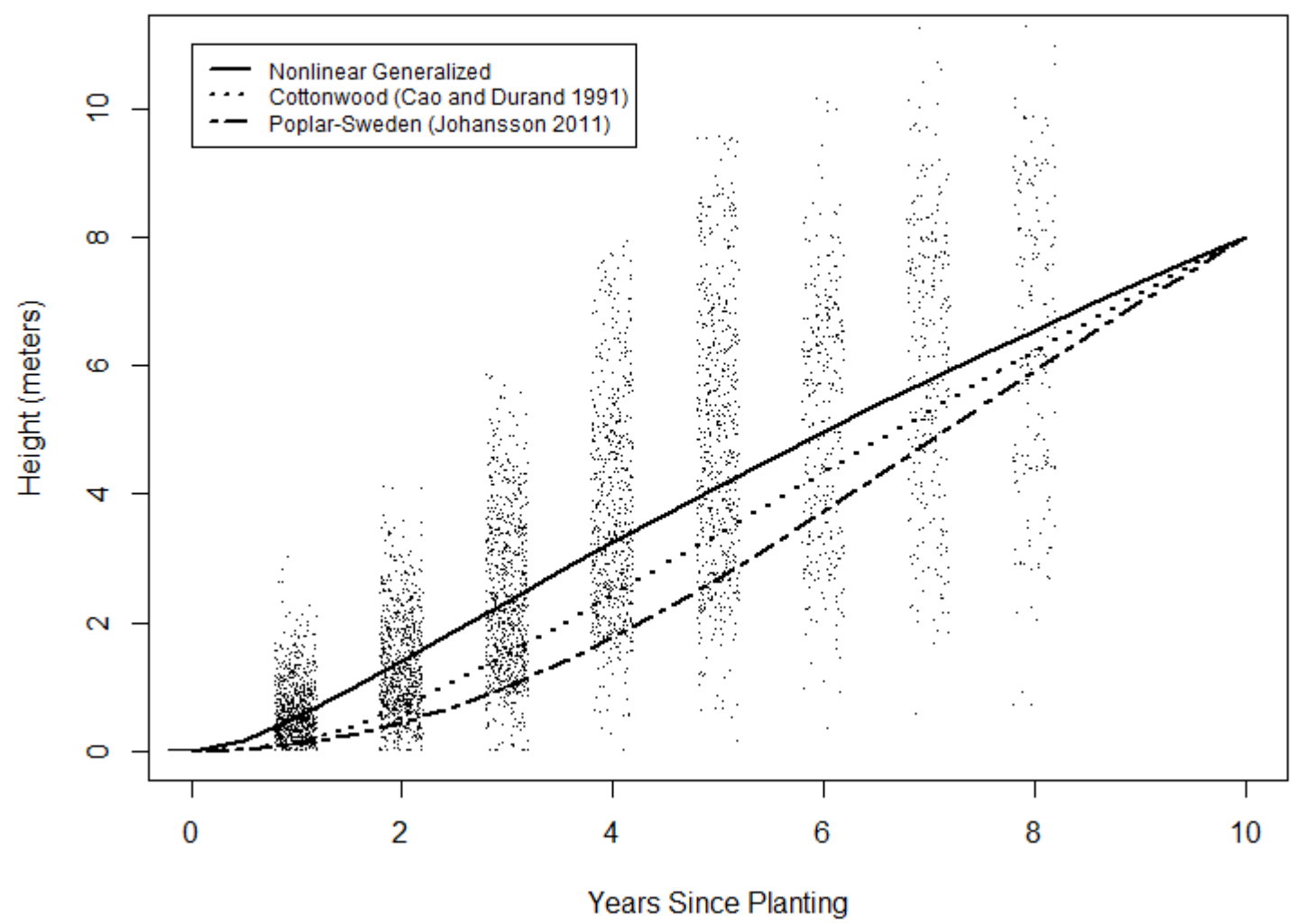

Figure 1.13. Comparison of generalized nonlinear model to short rotation eastern cottonwood (Cao and Durand 1991) and poplar in Sweden (Johansson 2011), site index value shown is 8 meters at 10 years post planting.

\subsection{Discussion}

\subsubsection{Base Model}

Creating maximum height/age values based on observations for each tree causes zero differences within difference approach models. For example, if the maximum height achieved is eight meters at seven years, then as we predict yield at the seventh year the difference of heights would be zero now that the tree has already achieved the height being modeled. These zero differences are linked to excessive flattening of curves near age 10 when difference approach equations are used (Burkhart and Tome 2012). This phenomenon creates the lack of fit for the suite of site index curves presented for both 
Schumacher models since they are both difference equations (Burkhart and Tome 2012).

Therefore, it is reasonable to conclude that using a method of site index modeling not requiring difference calculations is needed, such as Bailey \& Clutter or ChapmanRichards equations.

Visually, the Bailey \& Clutter model most accurately represents height progression (Figure 1.3). The Schumacher models both show rapid early growth with pronounced sigmoid form and inflection at 3-4 years post-planting (Figure 1.3). Chapman-Richards appears to model tree growth as a constant increase of height, not consistent with plantation growth.

The Chapman-Richards model may not be an appropriate fit for the hybrid poplar data due to the increasing growth rate of the curves near the base age, which can be seen in Figure 1.3. The other equation forms show a slight reduction in the growth rate as the base age nears. Use of the Chapman-Richards equation may cause issues if chosen as the base model due to this increasing growth rate near base age. The issue in question would be extrapolation beyond the time frame of 10 years post planting. If a user were to use the site index model for Chapman-Richards equation then modeling at 15 years may indicate a yield much greater than would typically be seen in a plantation.

The Bailey \& Clutter model was chosen as the base model for the ability of the suite of polymorphic curves to most accurately represent the realized growth of the hybrid poplar clones. The Bailey-Clutter model is also the model used in Cao and Durand (1991) plantation cottonwood site index models. Although our hybrid poplar BaileyClutter model and Cao and Durand (1991) short rotation cottonwood site index equation are modeling with tree species within the same genus and may have similar growth forms, we sought to expand the short rotation site index equation further to incorporate error due to autocorrelation.

\subsubsection{Nonlinear Mixed Effects Model}

The statistical difference found in the nonlinear mixed effects model shows a difference in the growth shape for each stock type. Stock type was shown to be statistically significant by Hillard (unpublished 2017) in his analysis of the same dataset, 
such that rooted and pole stock exhibited greater amounts of dieback compared to cuttings. The statistical significance of this hybrid poplar characteristic within the site index modeling could be dominated by this initial dieback of pole and rooted stock shown by Hillard (unpublished 2017). This dieback is modeled by the site index model and shown as the growth lines for poles tracing to a zero height until 3 years post planting in low site index values (Figure 1.11).

With the large number of observations, statistical significance can usually be easy to obtain. Since hybrid type and spacing were not deemed significant, these further underscores that growth form from NM6 vs. DN34 or planting density are quite similar. Even though it was not significant, the tree spacing of $6.1 \mathrm{~m}^{2} /$ tree appears to have a superiority of growth form over the other two spacing.

Work by Hillard (unpublished 2017) shows biological rotation for DN34 between 17 for poles and 27 for cuttings, and NM6 poles at 11 years and 20 for both rooted and cutting. This is longer than the current industry supposed rotation of 10 years.

Furthermore, under all proposed farm gate prices, land rental values, and discount rates, hybrid poplar never gained positive net present values. Showing that rotation age is still not defined accurately for the Great Lakes region, which impacts the proposed rotation length for our analysis.

It is helpful to note that our site index curves do not consider factors such as soil type, which may have a profound impact on the shape of the curves. Although soil was not directly tested, the plantations are located on a variety of soil types. Other confounding factors may include poor management of plantations after establishment. Within the plantation network weed control was often not properly maintained and thus trees exhibited reduction in early growth. There were also occasions when the appropriate herbicide was not applied and further hindered early growth.

Although interest in hybrid poplar ebbs and flows with such things as petroleum prices and carbon neutrality, this research is crucial in understanding growth form and geographic site productivity for this woody feedstock. Specialized site index models such as this can be used in geographic based regional model of productivity, like Deo (2014) or in regional biomass prediction models created by Hillard (unpublished 2017). As these 
GIS models become more refined and greater accuracy for biomass prediction, it can inform policy makers about hybrid poplar for renewable bioenergy. The site index model presented here can inform the Upper Great Lakes region about the potential of hybrid poplar as a woody feedstock.

Comparison of the generalized nonlinear mixed effects model to previously published site index curves (Cao and Durand 1991, Johansson 2011) for tree species within the same genus show superiority of fit for the generalized model. Both models under predict height for individuals until age seven, which encompasses almost the entire rotation age modeled. Since previously published site index curves for the same genus do not accurately represent the growth form seen in the Michigan Technological University Hybrid Poplar Network, these suite of guide curves would not be appropriate for use in the upper Great Lakes region.

For implementation of the generalized site index model a landowner must subtract the planted height from the total height for each individual tree. If the planted height is unknown, the average of each stock type may be sufficient and can be found in Table 1.2.

\subsection{Conclusions}

Differences in growth pattern with stock type is useful to know when considering the appropriateness of stock type for a given site. For example, if a specific stock type exhibits greater early growth, this could inform a landowner to plant that stock in areas of high animal browse which could grow above the browse line faster. Even though stock type was significant, utilization of that characteristic would be difficult to implement for a typical landowner since coefficients and categorical variables becomes increasingly complicated. Therefore, it is proposed that the generalized model would be best for widespread use.

Site index curves can help a landowner make decisions if hybrid poplar would create a productive revenue from biomass in established plantations. From the generalized model, around 3 years post planting a landowner can see if his/her site is high, medium, or low productivity. 
This site index model can further be implemented within spatial models to assess the hybrid/spacing/stock type combination that will provide desirable characteristics to a landowner. Equations for harvestable biomass can also be incorporated into our site index model to provide information on site productivity in terms of yield per unit area. This model can be used by forest managers and landowners to assess the site productivity and total expected yield of an existing plantation for each year. With the addition of plantation characteristics of stock type, the site index model is further refined to provide information on expected site productivity.

\subsection{Acknowledgements}

Thank you to the original funding sources of the poplar plantations: Wolverine Power, U.S. Department of Energy, and Michigan Technological University. Another thank you to all that have helped collect data over many growing seasons. 


\section{Analysis of alternative silvicultural prescriptions in Kirtland's warbler habitat, thinning scenario provides improved GHG emissions and production of timber}

\subsection{Abstract}

Current management of jack pine (Pinus banksiana) plantations utilized for breeding habitat by the Kirtland's warbler (KW) (Setophaga kirlandii) is based on 50year rotations with manual plantation establishment in highly mechanized opposing wave patterns. The opposing waves are created by planting rows in sine-type waves, where the following rows are in the opposite direction creating openings within the matrix of tree rows. The primary objective of this type of management is commonly to generate $\mathrm{KW}$ habitat. Our goal was to develop a set of three novel management prescriptions that could incorporate other objectives while also providing $\mathrm{KW}$ habitat. The four management regimes tested were: 1) business-as-usual (clearcut at 50-year rotation), 2) long rotation with natural regeneration (clearcut at 60+-year rotation with no residue pickup), 3) short rotation (clearcut at 25-year rotation), and 4) a thinning scenario (two thinning entries with final harvest at $60+$-year rotation). The four regimes were assessed on these three categories: 1) breeding habitat creation, 2) greenhouse gas emissions, and 3) yield of timber products. The Lake States Forest Vegetation Simulator was calibrated and used to simulate forest growth and harvest volumes. A life cycle assessment was conducted to test the four management regimes for its ability to store carbon and reduce greenhouse gas emissions. Life cycle assessment results indicate long rotation (years) initially stores more carbon, but trends negative, short rotation remains net negative and thinning achieves carbon parity between 125-150 years (high-low productivity) to BAU for carbon storage. Short rotation creates greatest usable habitat. Thinning produces the greatest total timber products. No single scenario achieved all objectives, therefore a land manager should select the desired objective(s) with creation of KW breeding habitat and choose accordingly. 


\subsection{Introduction}

Recently there has been great interest in biomass for energy purposes as an avenue to mitigate climate change. Carbon credits and carbon neutrality of biomass for energy are an area of contention not only in the forest, but also in Congress (this feels like a good place to add a reference. Research has been conducted into production of woody biomass solely for bioenergy (i.e. hybrid poplar, eucalyptus) (Zalesny et al. 2009, Gonzalez et al. 2011), but has come under fire for the need to change land cover types from agricultural or barren to intensive forest management. To provide a forest-based renewable energy source, while not impacting agriculture or changing land cover types, we propose modifying current management scenarios in high density, low-productivity jack pine (Pinus banksiana) plantations to grow and utilize currently non-merchantable materials (tops and slash) for emerging bioenergy markets.

These high density, low-productivity jack pine plantations are used as breeding habitat for the endangered Kirtland's warbler (KW). The U.S. Fish and Wildlife Service originally listed KW as endangered in 1967 and it is still listed as endangered (USFWS Environmental Conservation Online System 2017). The Kirtland's warbler overwinters in the Bahamas and travels north to breed in the Lower Peninsula and parts of Upper Peninsula of Michigan. The KW is also found in smaller numbers in Wisconsin as well as Quebec and Ontario in Canada (Wisconsin DNR 2014). These areas have sandy soils that are typically dominated by tree species capable of surviving on poor quality sites, such as jack pine (Wisconsin DNR 2014). These areas are also the natural southern limit of jack pine across North America (Figure 2.1).

The Kirtland's warbler establishes ground nests in young jack pine stands with adequate density and canopy cover to provide nest concealment (Walkinshaw 1983). Within these jack pine dominated stands, this bird will utilize areas with trees between 520 years total stand age at a height between $1.2-6.7 \mathrm{~m}$ with a minimum patch size of 12 - 32 hectares (Walkinshaw 1983, Wisconsin DNR 2014, Donner et al. 2008). The natural disturbance regime for jack pine forests is typically natural regeneration after stand replacing forest fires, creating pure or close-to-pure even aged stands (Rudolph and Laidly 1990). Within these high-density stands, the Kirtland's warbler utilizes areas 
exhibiting interspersed openings with low canopy cover (Probst and Donnerwright 2003, Wisconsin DNR 2014).

Due to endangered status, federal and state agencies actively manage to increase breeding habitat for the Kirtland's warbler. Annually federal and state agencies plant over 1,600 hectares of jack pine in an opposing wave pattern to provide enough habitat to continuously increase the number of breeding pairs (Michigan DNR Operational Plan, personal communication 2016). The number of breeding pairs has increased tenfold since being endangered species listed (Michigan Department of Natural Resources, U.S. Fish and Wildlife Service, and U.S. Forest Service 2015). Today, the number of breeding pairs is twice the original goal of 1,000 pairs (Michigan Department of Natural Resources, U.S. Fish and Wildlife Service, and U.S. Forest Service 2015). The success of revitalizing the Kirtland's warbler has been linked to implementation of jack pine breeding habitat plantations and parasitic Brown-headed cowbird control (Michigan Department of Natural Resources, U.S. Fish and Wildlife Service, and U.S. Forest Service 2015). Initial management was to create plantations and harvest at 50 years (Michigan DNR Operational Plan 2016). Currently early plantations are due for harvest, but exhibit less than desired sawlog volumes. Low sawlog volumes coupled with habitat usability comprise only a fraction of total rotation, leads land managers to question if the original 50-year rotation is the best management prescription available. With the original management plan in question, land managers are left to make decisions about silvicultural options. Differences could be implemented within stands in real time, but would take years to see results. Therefore, modeling the changes would be best to test novel silvicultural options. To remedy problems with BAU, novel management prescriptions were proposed that may be more effective at managing for breeding habitat as well as other uses such as timber or mitigating greenhouse gas emissions.

Currently there are challenges to business-as-usual management for Kirtland's warbler habitat management. First, plantation establishment is an expensive endeavor that requires use of planting stock since natural regeneration is not sufficient to restock stands after 50-year final harvest. Also, the 50-year rotations aren't long enough to produce much merchantable timber to help pay for plantation establishment. To accommodate for 
these challenges rotation length may be lengthened and allow for increased merchantability and natural regeneration. Conversely, rotation length may be shortened, producing more habitat and possibly more biomass. Lastly, land managers could perform silvicultural thinnings to increase residual diameter growth and may satisfy at least three desires: increase merchantable timber volumes, create biomass from thinning, and provide enough branches with attached pollinated cones for natural regeneration.

Within the agencies providing KW breeding habitat, land managers have many factors that influence their decision making. To assess the effectiveness of the four management regimes, criteria were established that would encapsulate the desired multiuse scenario in the breeding habitat. Chiefly in the concerns of a land manager would be 1) breeding habitat creation, 2) greenhouse gas emissions, and 3) yield of products.

Forest growth and timber produced was modeled with the Lake States Forest Vegetation simulator (LS-FVS). Biomass removals were modeled on harvest sustainability research of clearcut species in the region and estimates from published Michigan Department of Natural Resources (MDNR) timber prospectuses. Removed biomass from nutrient-rich, non-merchantable tops and branches may impact long-term site productivity and is important factors to consider.

Recovery of logging residues, even when no explicit effort is maintained to leave some material behind, usually results in significant volumes of material retained on site. For example, biomass recovery rate for quaking aspen (Populus tremuloides) in the Lake States is about $40 \%$; thus $60 \%$ is retained unintentionally, largely due to incidental breakage from winter harvests (Klockow et al. 2013, Rittenhouse et al. 2012). In jack pine forests in Ontario, Canada, Hazlett et al. (2014) determined full-tree harvests (72\% retention) and tree-length harvests (35\% retention) had similar carbon and nutrient removals. Therefore, with higher retention values the forest does not see an increase in nutrients left onsite, allowing for greater residual removal. MDNR current retention guides from 2016 timber prospectuses are 1/6 - 1/3 of non-merchantable tops and branches not chipped and left on site (MDNR published timber prospectuses, 2016). Our modeling followed the guide of leaving $35 \%$ of non-merchantable slash. 
Life cycle assessments are a widely-accepted method to help make decisions assessing environmental impacts from products or practices (Royne et al. 2016). Life cycle assessments have been successfully applied in a variety of carbon accounting scenarios for creation of biomass for bioenergy. For example, Jonker et al. (2014) studied the conversion of softwood plantations to produce biomass for pellet production at standand landscape-levels with a business-as-usual scenario of unharvested plantations. Furthermore, Mitchell et al. (2012) researched landscape-level changes in carbon storage from four separate landscape environments to varying harvest frequencies and intensities. Although research is extensive in this area, the life cycle methods are currently debated. Concern lies in the inclusion/exclusion of certain aspects of the life cycle assessment. For example, land-use change is important to consider if conversion to biomass production within a forest would cause direct changes to current forest type (farmland to biomass production) or indirect changes to surrounding forest (another forest changes due to biomass production) (Ter-Mikaelian et al. 2015). Another major point of interest in carbon accounting is the determination of baseline. As described by Ter-Mikaelian et al. (2015), three general baselines can exist: "no harvest," "traditional forest products," and "reference point" and refer to forest state without biomass production pressure. Determination of baseline is crucially important to application of life cycle assessment and accurately reporting emissions for biomass production (Ter-Mikaelian et al. 2015). Baseline choice also has impacts to carbon debt and time to carbon parity.

Carbon debt is the concept that an alternative scenario must repay the debt of carbon found in the baseline, and is repaid as the biomass production forest grows and offsets coal emissions. This idea is also the topic of many other life cycle assessments for bioenergy (Mitchell et al. 2012, Jonker et al. 2014). Problems arise in carbon emissions accounting when only the carbon debt, and not the carbon parity, is considered in a life cycle assessment (Ter-Mikaelian et al. 2015). Another concept of carbon accounting is the offset parity point, described as the point at which the novel prescription will sequester more carbon than the baseline and continue to sequester more carbon from forest products and use of the alternative fuel source. This approach requires the sum of all carbon flows both atmospheric and within the forest. 
Field measurements were taken to develop a FVS model that is calibrated to observed growth across Michigan. Using a developed LS-FVS model, life cycle assessment, and calculations for habitat usability, the four management regimes are assessed for the ability to meet the three criteria for land manager decision making.

\subsection{Methods}

The overall approach was to simulate a business-as-usual and three alternative silvicultural strategies, and then to characterize the life-cycle carbon emissions associated with each. Simulations were conducted using the Forest Vegetation Simulator (FVS; Dixon 2015), which is a widely-accepted forest growth and yield model. FVS includes a sub-component, the Fire and Fuels Extension (FFE; Reinhardt and Crookston 2003), that quantifies $\mathrm{C}$ pools and tracks the fate of harvested wood. Field data from a chronosequence of managed and unmanaged jack pine stands characteristic of KW habitat were used to calibrate and validate the FVS model before using the model to simulate forest development.

\subsubsection{Field Measurements}

Stands measured include areas across the range of jack pine in Michigan (Figure 2.1). Stands in the Lower Peninsula were owned and managed by the Michigan Department of Natural Resources, and stands in the Upper Peninsula by Michigan Technological University except for one stand on land owned by Weyerhaeuser Co. All locations are found on sandy soils commonly associated with glacial outwash plains (Web Soil Survey 2016). 


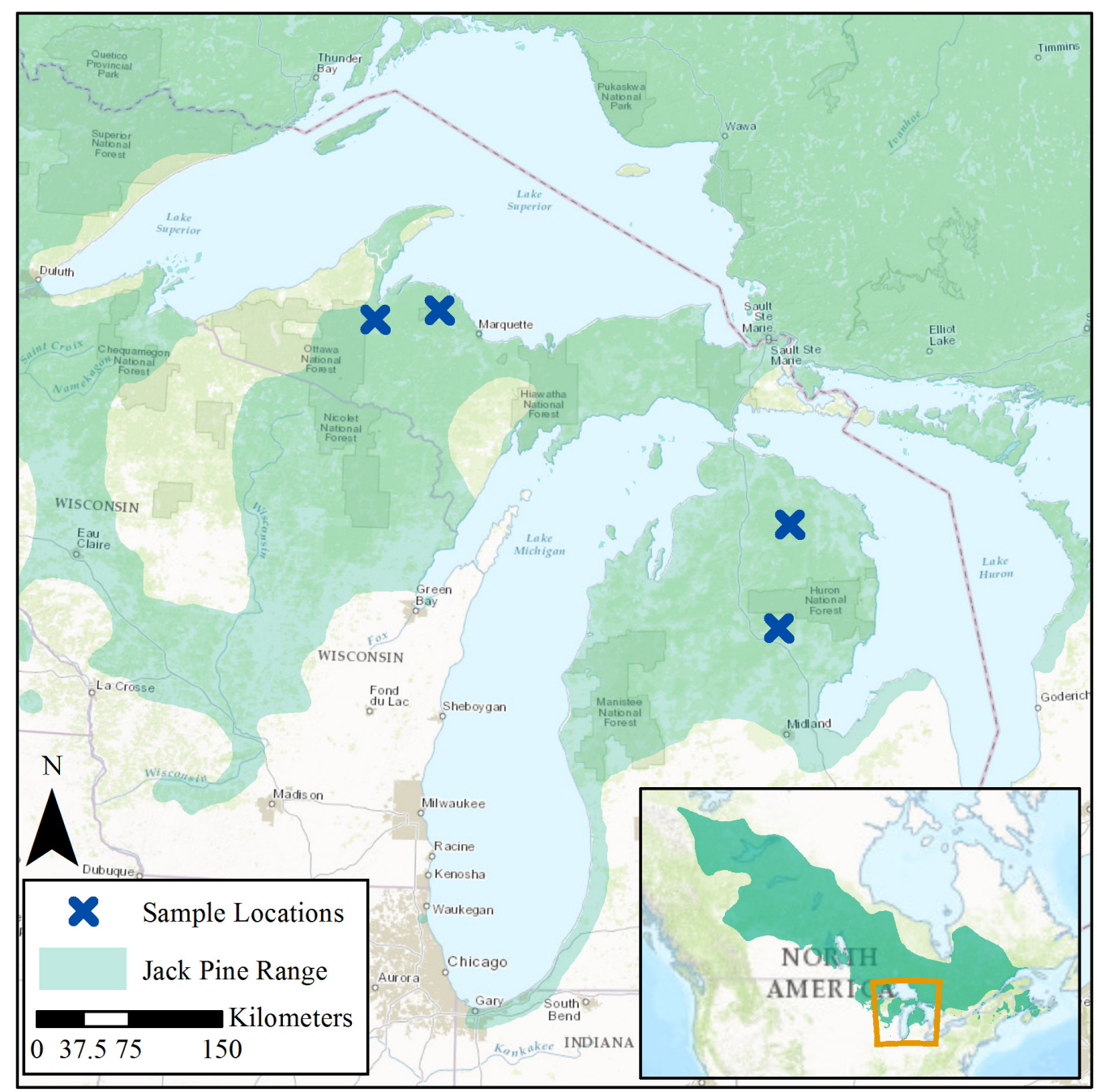

Figure 2.1. Sampling locations of natural and plantation jack pine stands across Michigan. Source: Little, Jr., E.L. 1999. Atlas of United States Trees. U.S. Geological Survey. Digital Version 1.0. Copyright: (C) 2014 National Geographic Society, i-cubed.

Sampled stands were selected purposively from a chronosequence of age (8-14, $15-21,22-29,32-49)$ to capture variability and ensure roughly equal sampling across the age range for extant KW plantations. Plot locations were selected randomly once on site. Natural origin stands were measured using a circular plot with plot size varying on stand density. Plot size was 1/100ha (5.64 m radius) unless local stand density was greater than 1,600 stems/ha, which were sampled using a 1/200 ha (3.99 m radius) plot. Plantation origin stands were sampled using rectangular plots with a fixed length $(12 \mathrm{~m})$ and width $(6 \mathrm{~m})$. Rectangular plots were established centered upon planting rows, but placed 
randomly on row length. Row spacing in jack pine managed for $\mathrm{KW}$ is consistently about 2 meter; hence, a 6 meter wide plot always captured 3 rows.

Table 2.1. Stand characteristics for the sampled jack pine stands.

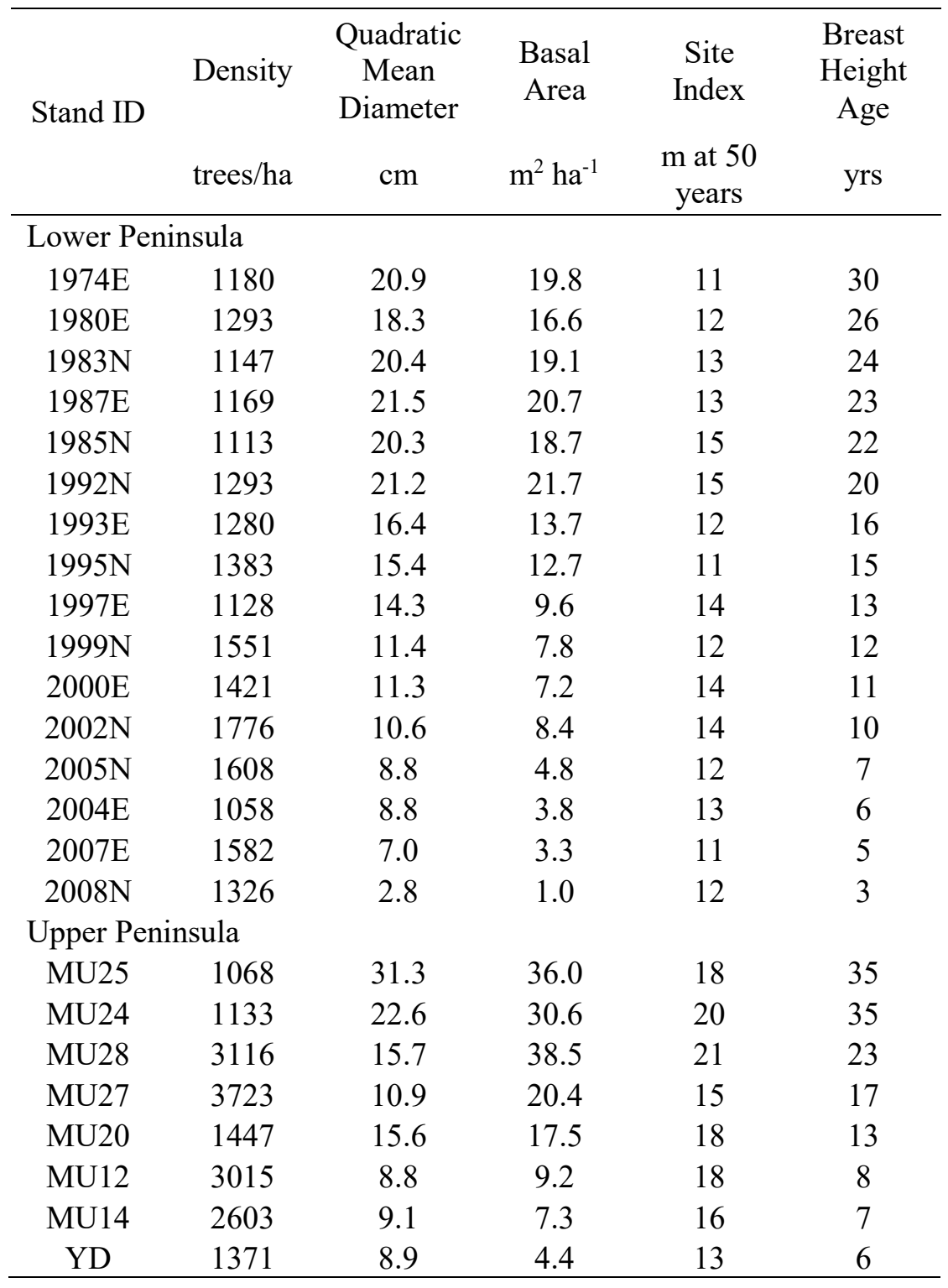

Within each plot, species, diameter at breast height (DBH), and tree status were recorded for all trees. Tree status was adapted from Forest Service Forest Inventory Analysis (FIA) specifications, and recorded in three categories: 0, 6, 9, based age of death and/or live tree (USDA 2016). Indicators of year since death were presence/absence of 
fine twigs or sloughing of bark. An appropriate site index tree was measured for total height and breast-height age, using an increment core. Height and height-to-crown base were measured on a subset of four additional trees per plot, which were then destructively sampled to obtain a breast height section (a "cookie") to determine diameter growth, and a stem segment at a measured height from the live tip to determine height growth. These samples were labelled and collected for processing in the lab. Cookies were stored frozen in plastic bags to prevent moisture loss and mold until they could be processed.

In the lab, the width of each growth ring along a radial transect from 2015 growth year down to pith was measured for each DBH cookie using a tree ring measurement system that employs a one micron resolution electronic linear encoder (Velmex, Inc., Bloomfield, NY) under a Leica MZ9.5 stereomicroscope (Leica Microsystems, Buffalo Grove, IL). These measurements were repeated on a second transect oriented 90 degrees from the original, and the latest measurements were averaged to estimate 10-year radial growth. Height growth was estimated dividing stem segments into two centimeter discs and examining each disc to determine origin of the annual height increment closest to age 10. Height growth was then derived from the measurement from tree tip to point of origin of height growth, and standardized to a 10-year base where necessary.

Breast height age from site index tree was used to calculate the site index value for the plot and averaged across the stand. FIA standards were followed for evaluating site index using the Gevorkiantz (1956) equation for jack pine. Time to breast height was determined separately for plantation and natural origin stands. 


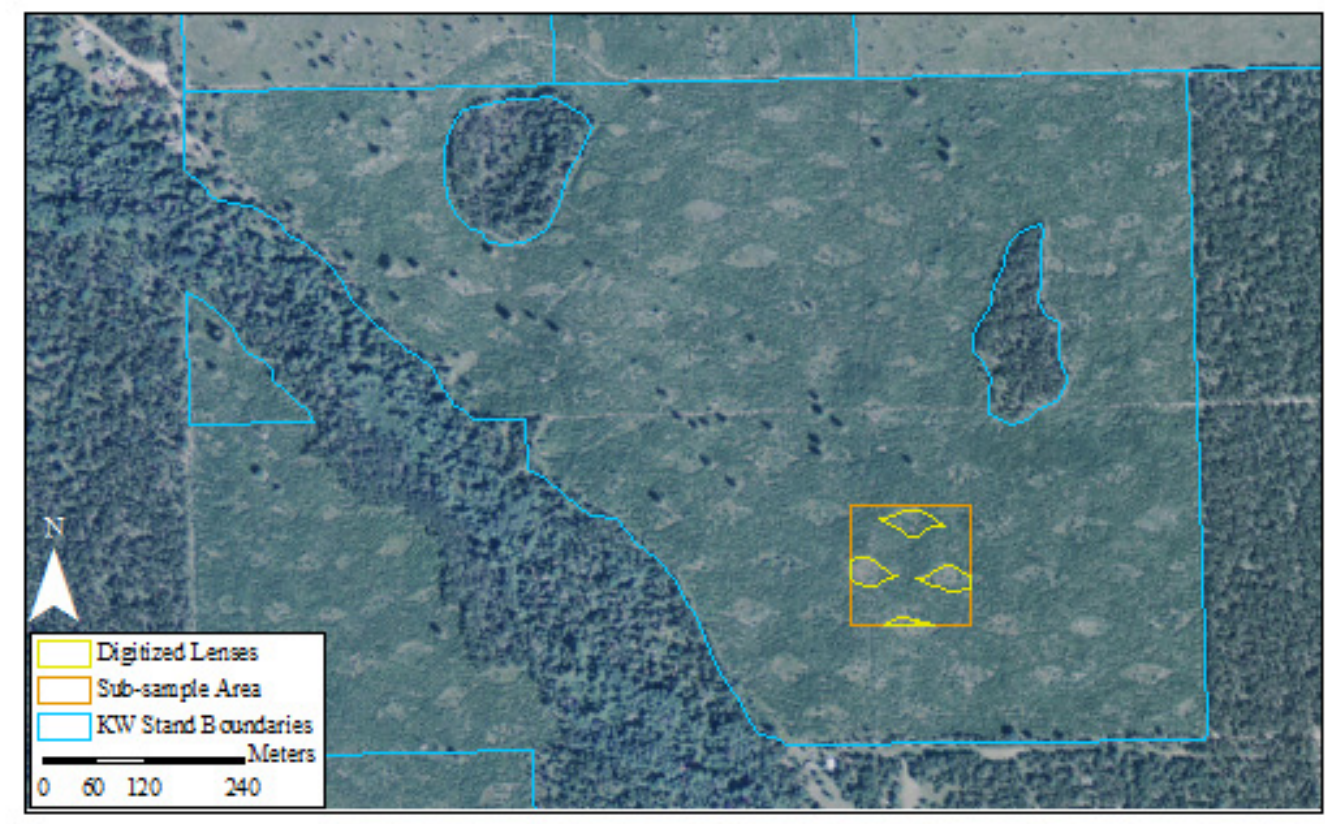

Figure 2.2. Example of digitized openings within jack pine plantation managed for Kirtland's warbler breeding habitat. Sources: Esri, DigitalGlobe, GeoEye, i-cubed, USDA FSA, USGS, AEX, Getmapping, Aerogrid, IGN, IGP, swisstopo, and the GIS User Community.

\subsubsection{Lake States FVS}

The FVS model is comprised of geographically-specific variants; for this work the Lake States Variant (LS-FVS; Dixon and Keyser 2016) was used. FVS is an empirical, individual-tree aspatial model, and for simulation trees are divided into two classes, depending on a threshold DBH. For trees under 5.0 in. DBH, diameter growth is modeled by solving the height model for $\mathrm{DBH}$ at both the beginning and end of the growth cycle from predicted heights and the difference between the end and beginning of cycle measurements is the diameter growth after adjustment for bark (i.e., height-driven growth). For trees over 5.0 in. DBH periodic increment is determined using potential growth times a competition modifier from LS-FVS (Dixon and Keyser 2016) then adjusted to the prediction cycle length, after which height increment is derived from Carmean et al. (1989) site index curves (i.e., diameter-driven growth). The transition between height-driven and diameter-driven growth is blended using a weight of the DBH over the size range, 1.5 in. -5 in. (LS-FVS; Dixon and Keyser 2016). A default 
projection cycle of 10 years may be modified by the user; for this work a cycle length of 5 years was selected to increase temporal resolution. The user-interface to the LS-FVS model is Suppose, and both are available for download from the USDA Forest Service website.

The current public release of LS-FVS is based on growth models from the TWIGS model (Miner et al. 1988) and has been shown to be biased in application (Pokharel and Froese 2008, Russell et al. 2015). For this project, a revised version that incorporates new large-tree DBH models developed by Deo and Froese (2014) was used. The new DBH increment model was fit using trees measured at consecutive intervals from the USDA Forest Inventory and Analysis program in the Lake States Region and included over 3,000 observations for jack pine site index. For details, see Deo and Froese (2014).

Though use of the revised model was expected to improve accuracy, improvements were confined to one sub-component (the large-tree DBH increment equation). To further tune the FVS model for this study the "self-calibration" feature was used. If enough periodic increment measurements are available in a simulation data set FVS can calculate a ratio of measured to predicted increment, and use this as a scale factor to tune future projections. By default, FVS requires at least 5 growth observations to calculate calibration factors for a given species. In this study, height and diameter growth measurements from field data were incorporated into the plot- and stand-level tables in the LS-FVS database, and calculated multipliers were output using the CALBSTAT keyword in Suppose.

Because multipliers are calculated at the stand level, the magnitude of any given multiplier could reflect overall model bias, or a stand-specific bias due to the inability of the model structure to completely capture stand-to-stand differences that explain variance in observed growth. In other words, multipliers could be related to site quality, geography, or stand density effects that are imperfectly represented in the internal structure of the FVS model. To test this, multiple linear regression was used to see if multipliers were statistically related to SI, latitude, density, or age. 
Stocked area in KW stands was estimated to assess the fraction of stands that are in productive tree cover. Six stands were randomly selected and within the stand boundaries a random two-hectare square was established spatially using ArcMap (ESRI 2011). Inside the random square, the openings were digitized, the area calculated and subtracted from the two-hectare total (Figure 2.2). The mean stocked area was $80.5 \%$ (SD $5.9 \%$ ) of total area and was applied in FVS.

Utilizing the multipliers and percent stocked area, the model was compared to chronosequence data from Rothstein et al. (unpublished 2016 data).

\subsubsection{Simulation of BAU and Alternative Management Regimes}

From field measurements, a marked difference was noted in productivity between the Upper and Lower Peninsula ( $\mathrm{SI}_{50}=17 \mathrm{~m}$ and $13 \mathrm{~m}$ respectively) stands; therefore, the locations were modeled separately. Per FIA data the mean jack pine site index value in Michigan is $17.8 \mathrm{~m}(\mathrm{SD}=3.3 \mathrm{~m})$ at 50 years (FIA, 2013).

Within LS-FVS, a single plantation establishment scenario was used across all management regimes: 715 stems/ha, $80 \%$ survival, one-year average seedling age, and planting one year after final harvest (Table 2). BAU and three alternative management regimes were simulated: "Long" where rotation length was extended to age of max MAI, "Short" where rotation was set at 25 years, and "Thin" where multiple thinnings were used to recover biomass and accelerate the attainment of merchantable size in residual trees. For Long, the rotation length was that corresponding with peak mean annual increment for sawlogs, and the same rotation length was used for Thin. The rotation lengths are as follows: low productivity, long and thinning regimes- 70 years, high productivity, long and thinning regimes- 60 years. Short rotation and business-as-usual was set at 25 and 50 years, respectively, regardless of productivity level (Table 2). Nonmerchantable residues, tops and branches, are simulated with $60 \%$ pick up, except for Long where left on site to promote regeneration from cones found on these branches.

Thinning schedules were determined separately for low and high productivity stands to maximize harvested forest products. Low productivity stands were modeled with row thinning at 40 years after plantation establishment, with residual basal area 17 
$\mathrm{m}^{2} /$ ha, representing approximately a removal of $32 \%$ of the stand volume across all diameter classes. Second thinning was simulated at 60 years post-establishment, thinning $38 \%$ of stand volume from below to a residual basal area of $18 \mathrm{~m}^{2} /$ ha. High productivity stands had row thinning at 30 years post-plantation establishment with residual basal area $16 \mathrm{~m}^{2} / \mathrm{ha}$ (34\% removal), and commercial thinning from below at 45 years with residual basal area to $17 \mathrm{~m}^{2} /$ ha ( $36 \%$ removal). The plantation schedules are repeated through the 200-year time horizon.

Table 2.2. Summary of silvicultural management for all regimes in both productivity classes.

\begin{tabular}{|c|c|c|c|c|c|c|c|c|}
\hline \multirow[b]{2}{*}{ Site Index } & \multicolumn{2}{|c|}{ BAU } & \multicolumn{2}{|c|}{ Long } & \multicolumn{2}{|c|}{ Short } & \multicolumn{2}{|c|}{ Thin } \\
\hline & High & Low & High & Low & High & Low & High & Low \\
\hline Regeneration & \multicolumn{2}{|c|}{ Plant } & \multicolumn{2}{|c|}{ Natural } & \multicolumn{2}{|c|}{ Plant } & \multicolumn{2}{|c|}{ Plant } \\
\hline 1st Thin & - & - & - & - & - & - & Age 30 & Age 40 \\
\hline \multirow{2}{*}{ Residual BA } & & & & & & & 16 & 17 \\
\hline & & & & & & & $\mathrm{m}^{2} / \mathrm{ha}$ & $\mathrm{m}^{2} / \mathrm{ha}$ \\
\hline 2nd Thin & - & - & - & - & - & - & Age 45 & Age 60 \\
\hline \multirow{2}{*}{ Residual BA } & & & & & & & 17 & 18 \\
\hline & & & & & & & $\mathrm{m}^{2} / \mathrm{ha}$ & $\mathrm{m}^{2} / \mathrm{ha}$ \\
\hline $\begin{array}{l}\text { Final Harvest } \\
\text { Age }\end{array}$ & \multicolumn{2}{|c|}{50} & 60 & 70 & \multicolumn{2}{|c|}{25} & 60 & 70 \\
\hline Residue Fate & \multicolumn{2}{|c|}{$60 \%$ Recovered } & \multicolumn{2}{|c|}{ Left on Site } & \multicolumn{2}{|c|}{$60 \%$ Recovered } & \multicolumn{2}{|c|}{$60 \%$ Recovered } \\
\hline
\end{tabular}

Carbon was modeled within LS-FVS using the Fire and Fuels Extension. Output follows the Jenkins et al. (2003) national biomass estimations and include fate of harvested merchantable carbon using Smith et al. (2006). Model estimates of wood C mass on a per hectare basis were converted to dry wood mass, assuming wood is $50 \%$ carbon (Ragland et al. 1991). Green wood mass was estimated by assuming freshly harvested wood is 50\% moisture on a mass basis (Miles and Smith 2009). 


\subsubsection{Life Cycle Assessment}

The life cycle assessment scope encompasses plantation establishment, stand growth, and product transport, use, and disposal (Figure 2.3). Included in forest carbon are above- and belowground carbon, standing and down dead wood, forest floor litter, and herbaceous layer. Equipment fuel and emissions were included in harvest and transportation of forest products. Product use and disposal was included for all product types.

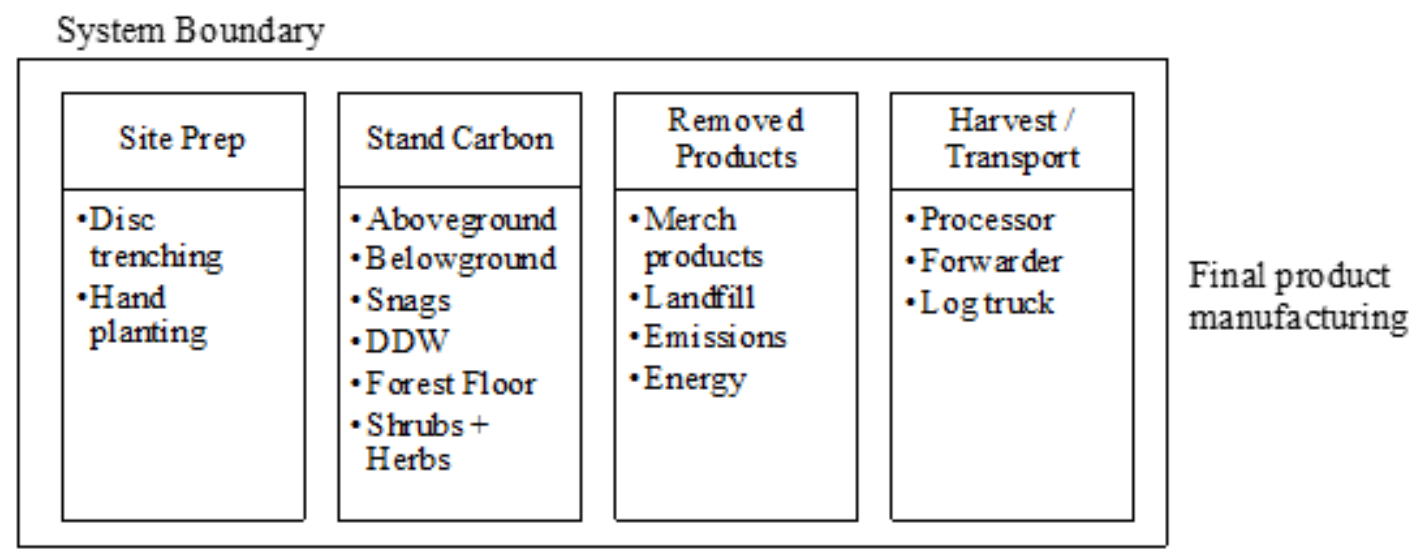

Figure 2.3. System boundary for jack pine plantation life cycle assessment.

The functional unit is one metric tonne of carbon per hectare with a timeline of 200 years. All scenarios start with bare ground, and do not include emissions from land use change. Indirect land use change was also not incorporated for changes away from BAU to novel prescriptions of short rotation or thinning.

Transportation distance was set at 100 kilometers, standard with other life cycle assessments (Handler et al. 2014, Jonker et al. 2014) but also representative of the actual stand distances from KW plantation areas in the Lower Peninsula to Grayling, Michigan. Grayling was established as the destination for wood transport due to the presence of a biomass power generating facility and a softwood lumber mill. Transport emissions were doubled to incorporate transportation to and from the mill.

Emissions from timber harvest and transportation equipment were evaluated based on findings reported by Handler et al. (2014). Harvest emissions were simulated using a 
processor/forwarder combination. For clearcuts the processor/forwarder emits $2.7 \mathrm{~kg}$ $\mathrm{C} /$ green tonne and $4.0 \mathrm{~kg} \mathrm{C} /$ green tonne for selective (thinning) cuts.

Harvested wood volume estimates are calculated in FVS using the USDA Forest Service National Volume Estimator Library and Scribner Rule for merchantable products (pulp and sawlogs) (LS-FVS; Dixon and Keyser 2016). Following Smith et al. (2006), FVS calculates the rate of merchantable wood still in use, emitted without energy, and found in landfills. All non-merchantable $(<7.6 \mathrm{~cm}$ inside bark diameter) wood products are assumed to be used as biomass for bioenergy production. Coal offset by wood energy was calculated at the conversion rate of $279 \mathrm{~kg} \mathrm{C} \mathrm{MWh}^{-1}$ coal / $406 \mathrm{~kg} \mathrm{C} \mathrm{MWh}^{-1}$ wood (Manomet Center for Conservation Sciences 2010).

Terrestrial carbon fixation and fossil $\mathrm{C}$ offsets are treated as positive and silvicultural and transportation emissions as negative, and the sum under BAU is treated as the reference case. Then, carbon flux is the difference between novel prescription and BAU carbon pools across the 200-year time horizon. A negative flux value demonstrates the alternative scenario is not sequestering as much carbon, and a positive value represents more carbon stored by the alternative management. The moment at which the novel management regimes exceed the BAU approach is termed the carbon parity point. For this analysis, a harvest was no simulated at year zero due to KW habitat creation mandate, therefore it is assumed that the plantation is established regardless of biomass production.

\subsubsection{KW Habitat Value}

KW habitat usability is a percent of total rotation spent in acceptable breeding habitat. Kirtland's warbler utilizes plantations from age 5-20, therefore the time in rotation in this range is usable habitat. Habitat usability is calculated for each combination of management regime and productivity level due to differing rotation lengths. 


\subsection{Results}

\subsubsection{Model Validation and Calibration}

Out of the 24 stands sampled, 22 had sufficient height growth samples and 5 had sufficient diameter growth samples to permit self-calibration within FVS. Output of the CALBSTAT keyword showed large tree diameter growth was being over-predicted (average multiplier $=0.872, \mathrm{SD}=0.105, \mathrm{n}=5$ ) and small tree height growth was under predicted $(\bar{x}=1.177, \mathrm{SD}=0.205, \mathrm{n}=22)$. The relationship between multiplier value and potential confounding factors was explored using multiple linear regression. Site index was the only factor significant with height multipliers. To adjust for site index correlation, a regression equation was derived $(\mathrm{F}(1,20)=5.59)$ :

$$
H M=1.676-0.011 \times S(\text { Equation } 2.1)
$$

Where HM is height multiplier and $\mathrm{S}$ is site index in feet. Therefore, for bareground scenarios the height multiplier was predicted for low and high productivity stands separately. The diameter growth multiplier was not correlated and was broadly applied.

With application of multipliers and percent stocked area, LS-FVS model follows the observed trend across stand ages well for multiple stand attributes (Figure 2.4). Data for young stands is missing or vary greatly for stand density values. Where the data is available the model performs well (Figure 2.4a). Basal area $\left(\mathrm{m}^{2} / \mathrm{ha}\right)$ predictions by LSFVS are consistent with observed data throughout observed stand ages (Figure 2.4b). Across the age range quadratic mean diameter is accurately predicted by the model (Figure 2.4c). Overall, the model predicts stand characteristics credibly across the observed age range from Rothstein (unpublished 2016 data). 

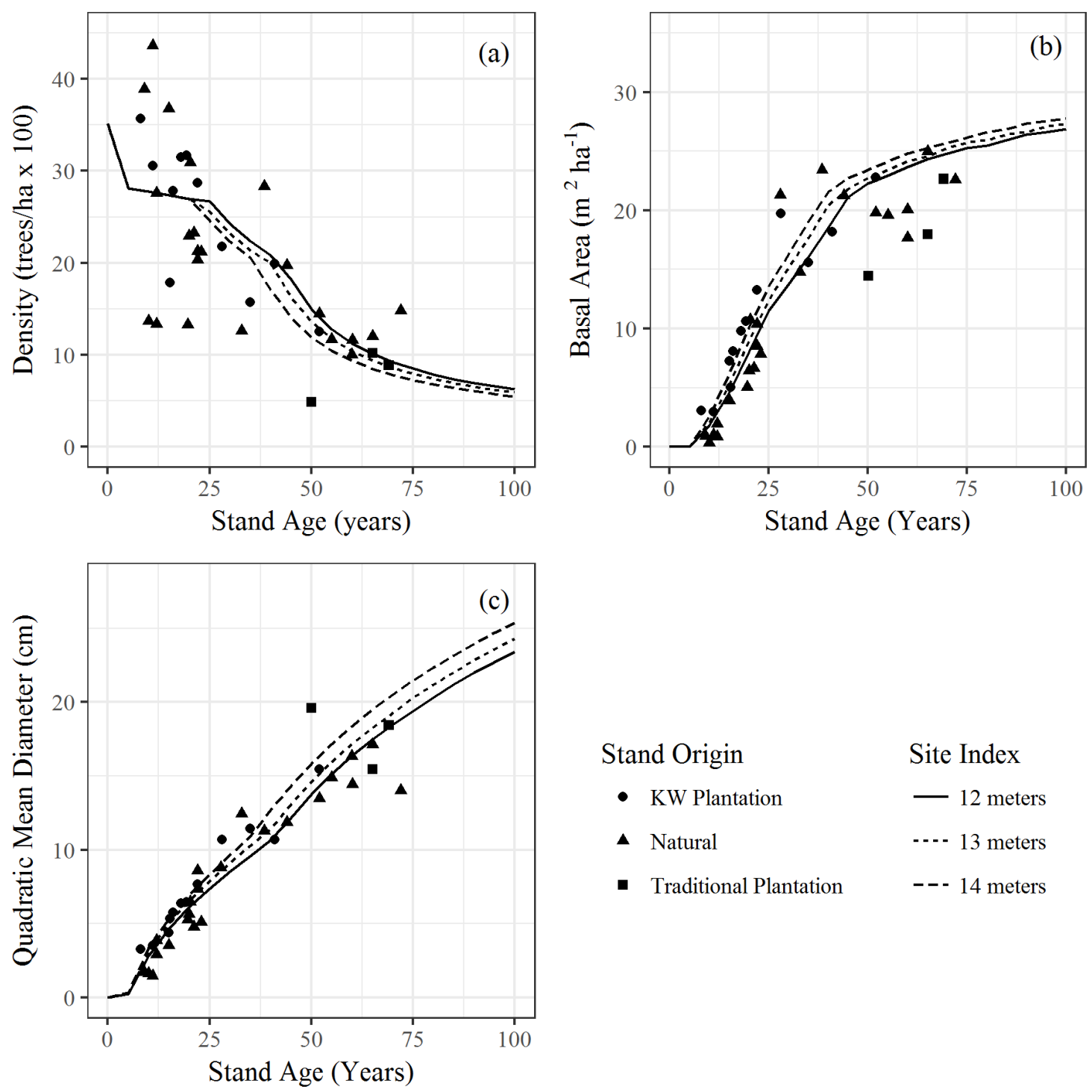

Figure 2.4. LS-FVS model stand attributes, (a) trees per hectare, (b) basal area, and (c) quadratic mean diameter, prediction plotted against Rothstein et al. (unpublished, 2016) chronosequence data in Lower Peninsula of Michigan.

\subsubsection{BAU and Alternative Silvicultural Regimes}

Short rotation management accrues far less forest carbon (aboveground live and dead, belowground live and dead, shrubs, herbs, and forest floor) compared to longer rotation lengths in BAU, Long, and Thin (Figure 2.5). In high productivity stands, greater amounts of carbon are seen in the aboveground pool across all management regimes (Figure 2.5, bottom row). In long rotation management, large amounts of aboveground 
dead (downed dead wood and snags) are amassed in the forest. Forest floor and herb carbon remains relatively constant across the entire time horizon (Figure 2.5, all panels). Pulses of aboveground and belowground dead material can be seen across all management and productivity levels, which are modeled as incidental breakage from harvest.
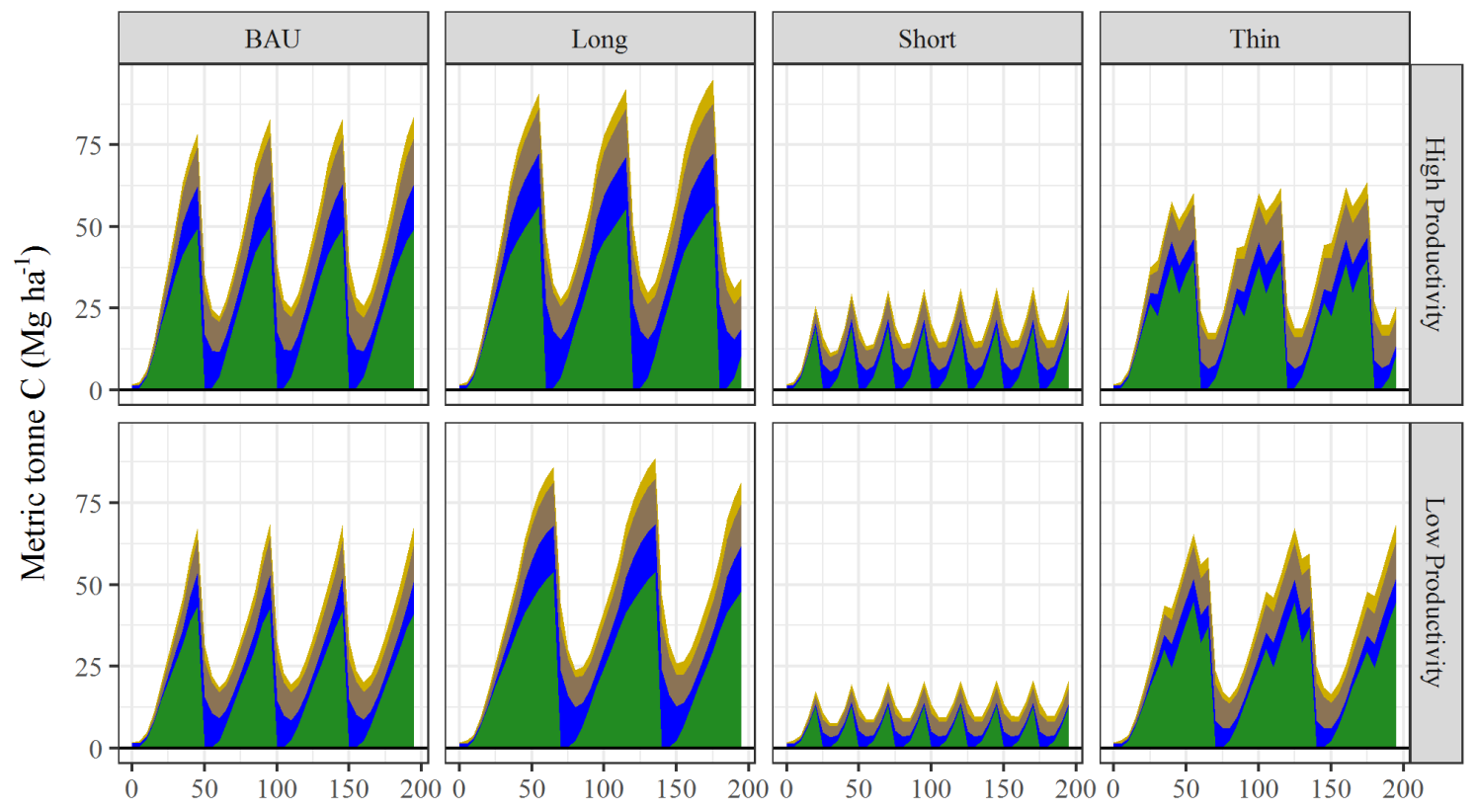

Stand Age (Years)

Carbon Pool Aboveground Live Aboveground Dead Belowground Dead Forest Floor + Herbs

Figure 2.5. Forest carbon pools modeled by LS-FVS across four management regimes in low and high productivity stands.

Short rotation management in low productivity stands yields no merchantable products (Figure 2.6). Landfill volumes increase with time as products are taken out of use, discarded, and accumulate (Figure 2.6). Although Long and Thin produce similar carbon in products and landfill at 200 year, the thinning management provides a more regular supply of products. With rotations only at 50 years, BAU produces less merchantable timber. 

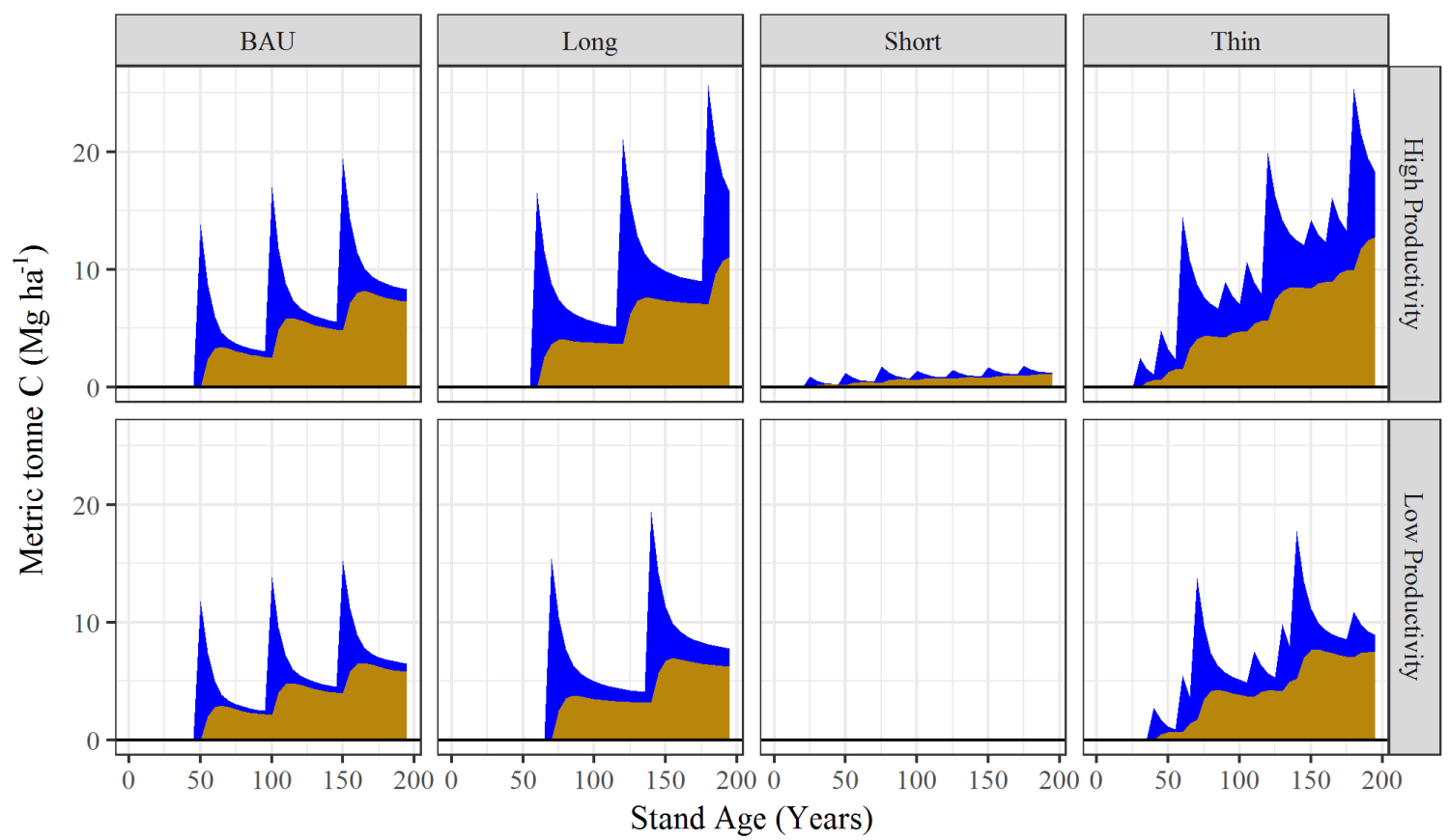

Carbon Pool Products Landfill

Figure 2.6. Merchantable product carbon pools simulated by LS-FVS with low and high productivity estimates across four management regimes.

With Long, a variety of forest products are attained at the end of rotation. In low productivity stands $10.3 \mathrm{~m}^{3} /$ ha of sawlogs, $155.8 \mathrm{~m}^{3} /$ ha pulpwood, and $17.7 \mathrm{Mg}$ of green chips per hectare are produced (Table 2.3). The amount of sawlogs is almost doubled for highly productive stands $-20.8 \mathrm{~m}^{3} /$ ha (Table 2.3 ). However, since BAU is managed for residue recovery it thus produces more biomass. The BAU management regime product volumes were compared to MDNR volume estimates from similar stands and found to be within the range seen in the forest (MDNR published timber prospectuses 2016).

Short produces the least diverse amount of forest products. In higher productivity stands, Short produces similar volumes of biomass as low productivity stands, but accumulates small amounts of pulpwood as well. Thin produces the greatest amount of total harvested merchantable wood. Low productivity stands produce $23.0 \mathrm{~m}^{3} / \mathrm{ha}$ pulpwood and $10.6 \mathrm{Mg} /$ ha of biomass in the first thinning, high productivity stands accumulate $21.3 \mathrm{~m}^{3} /$ ha pulpwood and $11.7 \mathrm{Mg}$ /ha of biomass (Table 2.3). The second 
thinning in both high and low productivity stands produce only pulpwood and biomass chips, but at the final harvest $21.1 \mathrm{~m}^{3} /$ ha of saw timber for high productivity stands and $5.9 \mathrm{~m}^{3} /$ ha in low productivity stands is also produced. At the end of rotation Thin provides the most biomass and pulpwood, but is about equal to BAU for sawtimber. In short, Thin provides the greatest product volume, BAU provides large biomass volumes and moderate pulpwood volumes, Long is intermediate to Thin and BAU, and Short provides only biomass (Table 2.3).

Table 2.3. Forest products per hectare in low and high productivity stands across four management regimes.

\begin{tabular}{|c|c|c|c|c|c|c|c|}
\hline & \multicolumn{3}{|c|}{ Low Productivity } & \multicolumn{3}{|c|}{ High Productivity } \\
\hline & & $\begin{array}{l}\text { Biomass } \\
\text { grn Mg/ha }\end{array}$ & $\begin{array}{c}\text { Pulpwood } \\
\mathrm{m}^{3} / \mathrm{ha}\end{array}$ & $\begin{array}{c}\text { Sawlogs } \\
\mathrm{m}^{3} / \mathrm{ha}\end{array}$ & $\begin{array}{l}\text { Biomass } \\
\text { grn } \mathrm{Mg} / \mathrm{ha}\end{array}$ & $\begin{array}{c}\text { Pulpwood } \\
\mathrm{m}^{3} / \mathrm{ha}\end{array}$ & $\begin{array}{c}\text { Sawlogs } \\
\mathrm{m}^{3} / \mathrm{ha}\end{array}$ \\
\hline \multicolumn{2}{|c|}{ Business-as-Usual } & 45.8 & 92.0 & - & 48.0 & 141.5 & 1.0 \\
\hline \multicolumn{2}{|l|}{ Long } & 17.7 & 155.8 & 10.3 & 18.5 & 185.3 & 20.8 \\
\hline \multicolumn{2}{|l|}{ Short } & 46.2 & - & - & 58.2 & 6.8 & - \\
\hline \multirow[t]{4}{*}{ Thinning } & 1st thin & 10.6 & 23.0 & - & 11.7 & 21.3 & - \\
\hline & 2 nd thin & 16.9 & 47.5 & - & 14.6 & 42.9 & - \\
\hline & Final cut & 36.4 & 111.3 & 5.9 & 39.5 & 138.4 & 21.1 \\
\hline & Total & 63.9 & 181.8 & 5.9 & 65.8 & 202.6 & 21.1 \\
\hline
\end{tabular}

Short rotation management has a 25 -year rotation regardless of productivity level; therefore, the habitat suitability is 15 years of a 25 -year rotation, equal to $60 \%$ (Table 2.4). Long and Thin within low productivity stands is suitable Kirtland's warbler habitat for $21 \%$ of total rotation (Table 2.4). Similarly, in high productivity stands BAU and thinning management is suitable habitat for $25 \%$ of total rotation length (Table 2.4). Shorter rotations of 50 years in BAU is suitable for $\mathrm{KW}$ habitat for $30 \%$ of rotation for both productivity levels. 
Table 2.4. Percent usable KW habitat (stand age between 5-20 years) for four management regimes in low and high productivity stands.

\begin{tabular}{ccc}
\hline & Low Productivity & High Productivity \\
\hline Business-as-Usual & $30 \%$ & $30 \%$ \\
Long & $21 \%$ & $25 \%$ \\
Short & $60 \%$ & $60 \%$ \\
Thinning & $21 \%$ & $25 \%$ \\
\hline
\end{tabular}

\subsubsection{Life Cycle Assessment}

Large amounts of carbon accumulate as coal credits under Short because all forest products are applied to offset coal for electricity generation, and therefore provide the largest sum of replaced coal carbon (yellow section, Figure 2.7). Emission from harvest, transport, and plantation establishment were pooled as "silvicultural emissions", and shown as a negative value for the carbon that is emitted to the atmosphere from equipment (grey section, Figure 2.7). Silvicultural emissions were of little overall significance compared to other carbon pools (Figure 2.7). Larger amounts of dead forest materials in Long are residuals left onsite to facilitate natural regeneration (brown section, Figure 2.7). BAU has greater coal offsets than Long, even though the rotation length is shorter, because residues are recovered to facilitate planting and used for power generation. Thin in high productivity stands produces the largest amount of stored carbon in products, overall. 

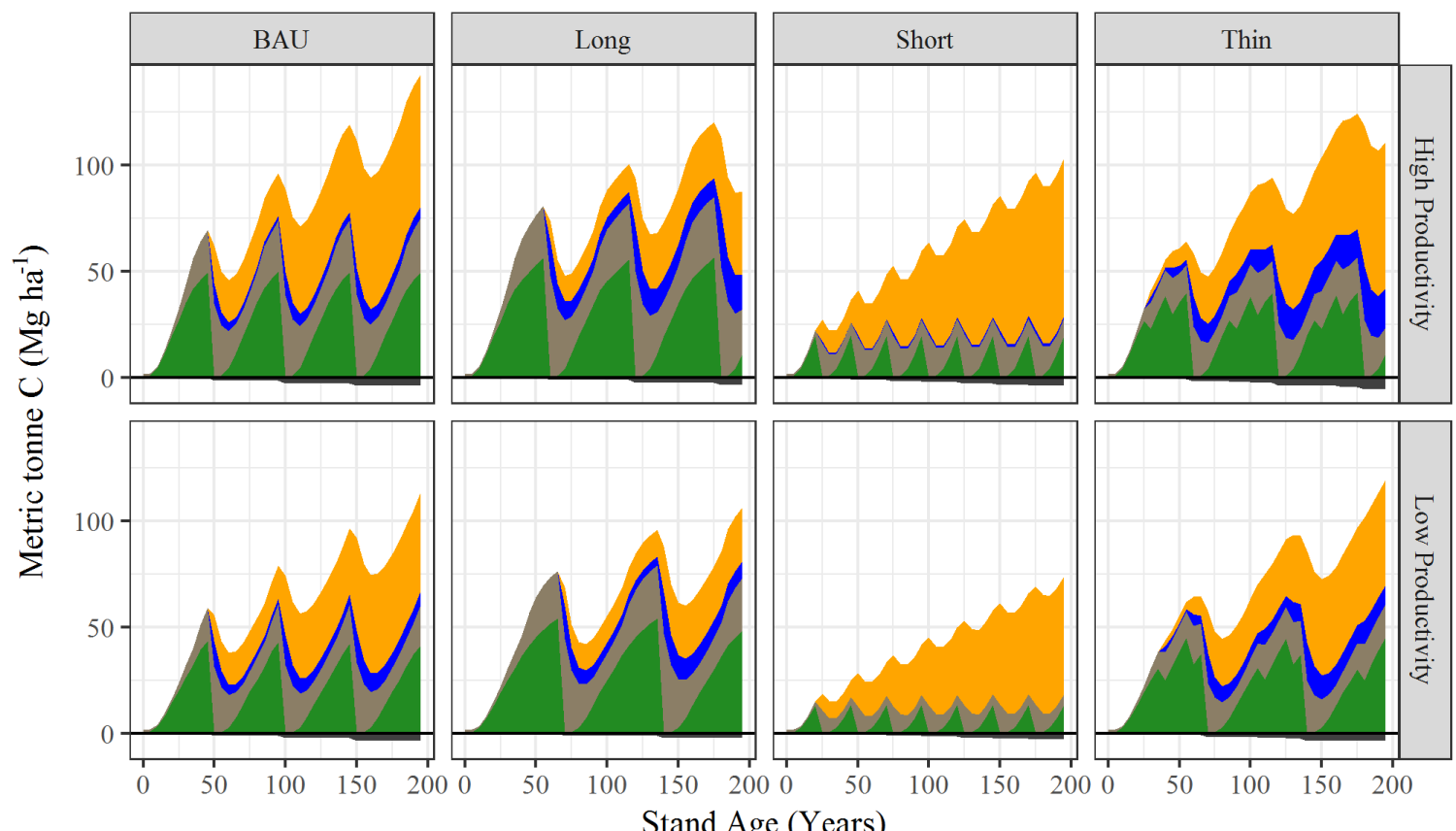

Carbon Pool

Forest Live Forest Dead Products Coal Credit Silvicultural Emissions

Figure 2.7. Carbon emitted and stored, as simulated by LS-FVS, with low and high site productivity values across four management regimes.

\subsubsection{Net Carbon}

When all carbon pools are summed, the difference between novel prescriptions and BAU can be directly compared. BAU is considered the baseline and represented as a black line at zero through the timeline. Both Short and Thin become net negative early in the time horizon since harvests begin in these regimes while carbon is still growing in BAU.

In general, higher productivity stands achieve carbon parity sooner (Figure 2.8, top panel). The high productivity thinning regime is the first to cross, and stay above, the solid line and is storing more carbon than BAU at stand age 125 years (Figure 2.8, orange line). Short rotation initially is the worst choice for carbon sequestration, but begins to trend upward. Short rotation does attain carbon parity in the high productivity stands around age 180 years, but is likely to be net negative for one rotation past 200 years 
(Figure 2.8, green line). Long rotation management initially stores more carbon, but trends toward net negative.

Short rotation management, compared to BAU stands, never becomes net positive for carbon storage in low productivity stands. The general trend for the thinning regime in low productivity stands trends net positive across the 200-year horizon. The low productivity thinning regime achieves carbon parity at around age 145 years (Figure 2.9). The low productivity short rotation stand never crosses the zero line and will remain a negative flux within the 200-year time horizon and likely far beyond it. Long rotation is also an initial net positive in low productivity stands, but also trends downward.

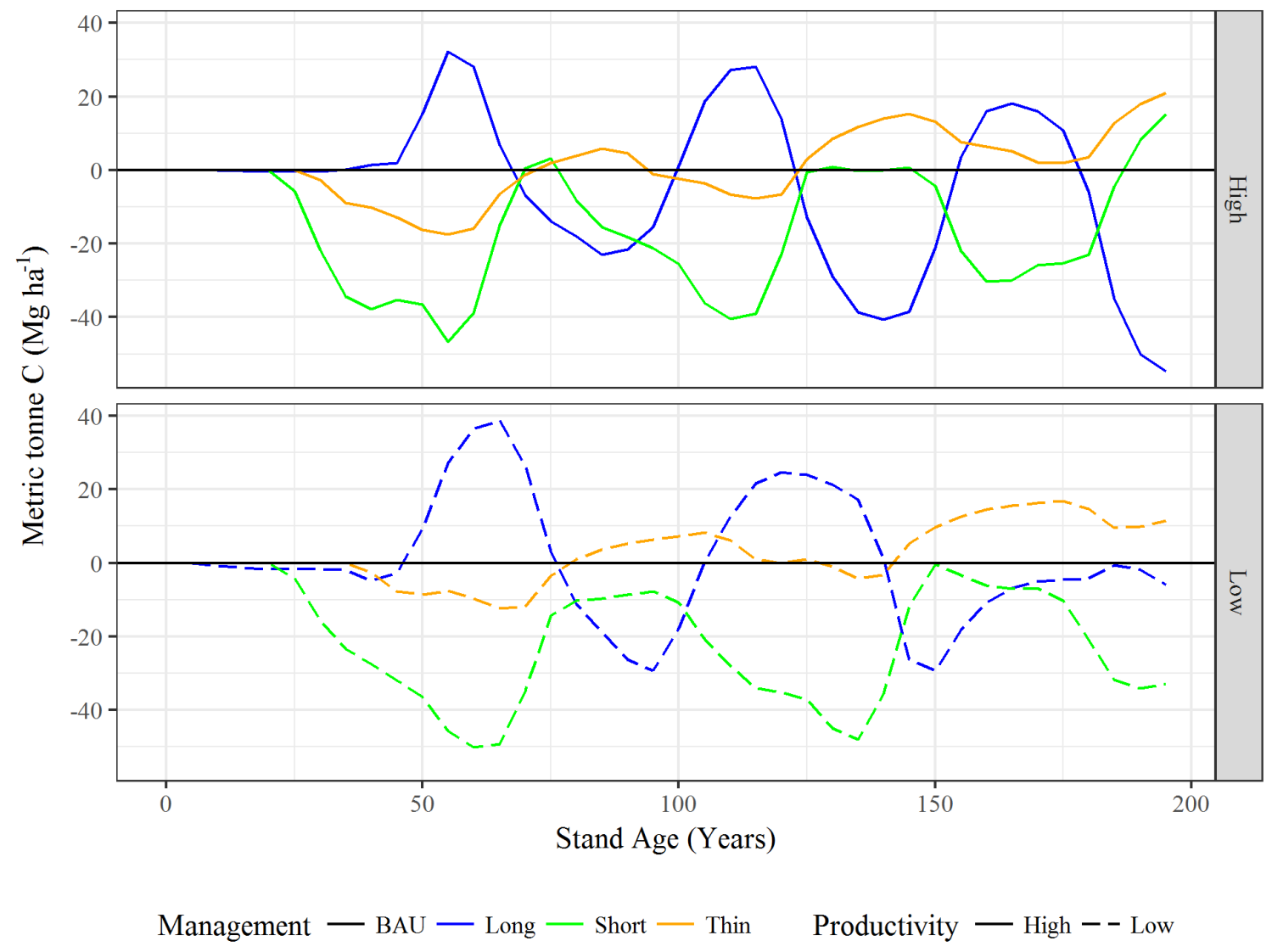

Figure 2.8. Time to carbon parity for carbon fluxes in thinning and short rotation regimes within low and high productivity stands compared to manual regeneration BAU. 


\subsection{Discussion}

\subsubsection{Model Validation and Calibration}

LS-FVS is known to bias diameter growth estimates (Russell et al. 2015, Pokharel and Froese 2008). To combat this problem, growth measurements were incorporated into FVS creating multipliers that adjust diameter and height growth through the simulated time horizon. The use of multipliers follows previous research such as Russell et al. (2015) where performance of LS-FVS was tested in Picea glauca plantations. Incorporation of multipliers allowed for reduction of LS-FVS bias for both diameter and height growth (Russell et al. 2015). Although diameter and height growth were both measured at location, FVS only utilizes one growth characteristic for each tree depending on DBH. Since FVS only predicts diameter growth for trees greater than 5.0 inches DBH, most of the diameter growth field observations (due to being less than 5.0 inches) were not able to be incorporated into the database to tune FVS.

Site index values were assessed using coarse adjustments from breast height age to total age from Gervorkiantz (1956). Our field methods did not include sampling the time to breast height, therefore it had to be determined from the field data collected. Plantation stands were adjusted to grow to breast height two years faster than Gervorkiantz (1956) and Upper Peninsula natural origin stands grew one year faster. Additional field samples could be collected to calculate the growth rate to improve estimates of site index values.

\subsubsection{Comparison to Literature}

An analysis of the literature shows that no biomass life cycle assessments include a baseline with biomass for bioenergy in the business-as-usual scenario, as with our analysis. With this analysis, conversion away from BAU was not merely intensifying production or forest conversion, but rather the possibility of not harvesting biomass with other standards such as introducing thinning or changing rotation length. Since this BAU scenario is not a "no harvest" baseline the parity point is aiming at a dynamic goal. This analysis shows a new aspect to carbon accounting for biomass production where a baseline scenario already includes bioenergy production. The novel prescriptions 
proposed are generally a stark contrast to alternatives found in literature; most alternatives test the introduction of bioenergy into a forest system, or increasing productivity (i.e. fertilization), or shortening rotations. Although Short is just a shortening of rotation, Long and Thin are novel contributions. Long is opposite of most novel prescriptions since we are analyzing no bioenergy against a BAU with bioenergy production. Furthermore, Thin is proposed as a complex thinning regime to increase bioenergy and traditional timber products. Therefore, direct comparison to literature may not be possible, but could be analogous to draw conclusions.

As with previous studies, and a consensus in biomass science, there is an initial net carbon emission to atmosphere with conversion biomass production. But the initial negative balance is paid off as coal is taken out of use and carbon saved, the carbon debt. As coal credits accrue the time needed to bypass the business-as-usual is of importance, the carbon parity point.

One novel approach to KW plantation management was conversion to short, 25year rotations and required the longest time to $\mathrm{C}$ parity, likely due to slow growth rates in young plantations. This slow growth coupled with short rotations then exhibits low aboveground carbon storage and, as Mitchell et al. (2012) stated, longer time for carbon sequestration parity. Further, Mitchell et al. (2012) studied the effect of light harvests (50\% removal) and observed less time to achieve parity, similar to differences between Short and Thin. Our results are also consistent with Jonker et al. (2014) showing that high productivity stands achieve carbon parity quicker than lower productivity stands, due to increased harvest volumes offsetting coal emissions which cumulate through the time horizon.

Our results show the difficulty in assessing carbon parity at the stand level. The parity point is a moving target as both BAU and novel prescription stands grow and harvested. Because parity is a moving target, it is difficult to definitively say when each management regimes achieves a total carbon parity. Comparing BAU-Long, BAU-Short, or BAU-Thin is difficult as net carbon fluxes rise and fall about the zero line - see Figure 2.8. Therefore, trends from management regimes, rather than time to parity, may be of distinct importance. Thin has the least variance and shows a generally trend upwards. 
Short trends negative until end of 200-year horizon, and even longer for low productivity stands. Long generally is negative, without any turn towards a positive carbon balance, due to non-recovered residuals.

Our results show a much longer time to carbon parity than other publications, likely due to the BAU baseline including bioenergy. Jonker et al. (2014) showed standlevel analysis had the longest time to parity at 46 years for low productivity stands. This could also be partially explained as Mitchell et al. (2012) also found, that lower productivity stands take longer to achieve carbon parity and the jack pine stands are generally low productivity compared to other tree species on better soil types. Manomet Center for Conservation Sciences (2010) showed that carbon debt was repaid at the latest within 32 years in forests in the Northeast US with biomass replacing coal for electricity generation, but did not include a parity point. Zanchi et al. (2012) found that payback times in new plantations were 114 years in low productivity sites when coal was being replaced.

Other studies include changes to soil carbon from harvests (Zanchi et al. 2012), but were not include in this analysis. Changes in soil carbon was tested by LeDuc and Rothstein (2007) and found there was no difference in soil carbon in 3-6-year-old clearcut jack pine stands and mature jack pine stands. Furthermore, there are no significant changes in soil carbon between whole tree harvest and natural origin stands across the whole soil (Rothstein and Spaulding, 2010).

For forest carbon pools simulated with LS-FVS, a "spin-up" time was not included because there were no substantial changes in background carbon pools from 0 150 years. Inherent with LS-FVS, soil carbon values across time are taken from Smith et al. (2006). Therefore, not requiring a "spin-up" time needed with other models, i.e. LANDCARB (Mitchell et al. 2012) and CBM has an automatic spin-up feature. There may be a difference between the average values from Smith et al. (2006) and the carbon volumes in the jack pine plantations sampled. These pools are also relatively small compared to avoided coal emissions or aboveground live forest pools.

Concerns have been brought forward about intensification of silvicultural practices and harvest removals to promote biomass production. Research into effects on 
soil nutrients following varying harvest intensities has been conducted across many forest types in the Great Lakes region (Hazlett et al. 2014, Premer 2015, Hendrickson et al. 1989). Hazlett et al. (2014) determined jack pine growing on sandy soils exhibited increased growth following increased biomass left on site, therefore intensive residue removals may impact site productivity. Not included in Hazlett et al. (2014) which was atmospheric deposition of nutrients. Specifically, atmospheric deposition of nitrogen that may offset removals of nutrient-rich twigs and branches. This analysis does not simulate any changes in productivity with any of the management regimes currently used or proposed. Current BAU utilizes intensive silvicultural for plantation establishment, which may reduce nutrient-rich fine branches left onsite that maintain nutrient balance. If substantial nutrient losses occur and not replaced from atmospheric deposition then site degradation will happen and further delay time to carbon parity.

Preliminary data from Rothstein (unpublished 2016 data) shows nitrogen losses of $15 \mathrm{~kg} / \mathrm{ha}$ has been recorded in clearcut stands that were trenched and planted. With these deposits, the nitrogen losses from harvest could be replaced in 10 years, sooner than even short rotation. Further analysis could be completed to simulate the effects of degrading site index with additional harvest.

Areas managed for KW habitat already exhibit pressure for breeding habitat creation, therefore forest types other than jack pine can be converted to plantations regardless of biomass creation. This mandate to create breeding habitat sets the assumptions for the baseline in this analysis such that no land-use change emissions should be incorporated. If large-scale biomass implementation was expected without KW habitat creation, land-use changes should be included in the life cycle assessment. The need to assess land-use change is stated by NCASI (2013), Ter-Mikaelian et al. (2015), and Royne et al. (2016). Royne et al. (2016) explain the importance of including land-use change not only from direct forest conversion to biomass production, but also indirect land-use change from increased pressures on the land for biomass. This analysis focuses on stand-level carbon dynamics, therefore direct or indirect land-use change was not incorporated because it is outside the scope. Furthermore, land use change in a managed forest landscape is small and difficult to quantify in such a small system. The Kirtland's 
warbler plantations system is a small portion of the total land base of jack pine across the habitat range in the United States or Canada and within all forested landscapes in northern Lower Peninsula of Michigan.

\subsubsection{Original Considerations}

The original three management criteria were: 1) breeding habitat creation, 2) mitigating greenhouse gas emissions, and 3) yield of products, and when all three criteria are assessed no single scenario achieved all objectives. Therefore, a land manager would have to determine which of the criteria is the most important to a piece of land and decide.

\subsubsection{Habitat}

The short rotation management regime creates the most usable habitat across the 200-year time horizon. If land managers switch to this style of management, the total number of acres tied up in Kirtland's warbler breeding habitat may decrease due to faster turnover. Short rotation management may also produce indirect land use change across the landscape from removal of land from KW habitat or sparing a forest from conversion to a KW plantation. If Short is implemented total acreage devoted to KW plantations would decline, thus allowing other forest types to remain intact or allow to become old growth.

The management regime of short rotations fared worse than initially expected. This may be due to selection of rotation length of 25 years. The lower productivity stands are unable to achieve meaningful growth to create wood products as with longer rotations. Creating a "short" rotation that was 5-10 years longer, or roughly half of the time to peak MAI (currently only $36-42 \%$ of MAI), may all short rotation to be more competitive in net carbon. Twenty-five years was selected to minimize mortality due to self-thinning rates currently seen within plantations of Rothstein chronosequence data (unpublished 2016). Allowing for some mortality may be offset by greater merchantability across the whole stand. 


\subsubsection{Mitigating Greenhouse Gases}

Thinning regime results in parity with business-as-usual stands faster than short rotation. If a land manager's singular goal was to offset coal emissions, then shifting current management to Thin would be the ideal option. Although the average of low and high productivity stands is currently negative, the trend for short rotation seems to be slightly positive. This would hint that short rotation may achieve parity with BAU in the future, past the 200 years simulated. Long rotation with natural regeneration is the least ideal option during the 200-year time horizon, since the overall trend is negative. The initial goal for Long was to leave non-merchantable tops and branches on site to mitigate natural regeneration, not sequester more carbon, therefore this may not be a direct comparison.

Time to repayment of carbon debt was not addressed in this analysis. The concept of carbon debt is arbitrary based on which carbon pools are considered and still under much scrutiny (Ter-Mikaelian et al. 2015). Furthermore, carbon debt repayment draws readers to assume that the new management guideline is more carbon neutral than the baseline, i.e. the idea that after repayment all carbon is a net positive. This work focuses only on the concept of carbon parity because this concept does not rely on arbitrary settings for a "debt".

\subsubsection{Forest Products}

Managing specifically to produce timber products would be favored by the thinning management regime. Switching to this style of management in a jack pine plantation would require strong biomass markets, now and in the future, for products from thinning. Currently, biomass markets in the area are not strong enough to warrant increasing production to the level we have simulated (Manomet Center for Conservation Sciences 2010). If the price for biomass were to increase, and thus increase demand, then increasing production would be logical. Unfortunately, the current and future markets for biomass are not likely to gain in prices due to low petroleum prices and abundance of other renewable energy sources (Manomet Center for Conservation Sciences 2010). Managing at long rotations produces pulpwood and sawlog volumes like the thinning 
regime, but a much-decreased weight of biomass chips. Therefore, if chip markets are not strong, this could be the favored management regime.

If there is no option to lengthen rotations to 60-70 as simulated in Thin or Long, then strategies must be employed to achieve carbon parity while keeping average rotation length low. One possible solution would be combining Thin or Long with Short across the landscape, allowing for intensive KW habitat creation in some areas while other product merchantable timber products. A combination of Long and Short management may offer a benefit over Thin and Short since there are no additional entries from thinning, but would come at a disadvantage from letting non-merchantable volumes decay on site. This difference is seen in the simulations as the large amounts of dead material accrue in Long from increased mortality rates toward the end of rotation and residuals left in stand post-harvest.

If a landowner's concern is creating the most Kirtland's warbler breeding habitat, without much regard for greenhouse gas emissions or forest products, then short rotations may be favored. Conversely, if production of high-quality forest products is of greatest concern then a land manager may shift towards a thinning regime or maintaining the business-as-usual management plan.

\subsection{Future Recommendations}

Financial viabilities were not included in this analysis due to limited scope and KW habitat creation mandate. Since the Kirtland's warbler is an endangered bird species, the Michigan agencies have a mandate to create breeding habitat, therefore financial considerations are secondary. Including financials into the analysis may have consequences for short rotations or thinning operations. Due to the limited product volumes from these two operations, financial incentives for loggers to bid on timber sales will also be low. Reducing the number of thinning operations, and thus reduce forest entries, in the Thin regime would reduce financial loses. Short management could offer no such solution. Loggers are needed to perform clearcuts and land managers need to plant every 25 years. One possible remedy may be financial subsidies for marketable materials to increase profits and interest in typically low-profit operations. For this 
scenario to be applicable, policy environments have to be such that there is a desire to offset carbon emissions from Thin and create biomass from thinning operations or Short management. Combination management of Thin/Long with Short would probably not offer any improvement financially, due to increased plantation costs of Short management.

Not included in analyses were emissions from mill operations. Although mill emissions may be small compared to other forest product pools, this aspect could be included to highlight differences between forest product types, i.e. softwood lumber mill vs. energy input for bioenergy production. Not including these emissions would only penalize the scenarios that produce forest products, all but low-productivity Short.

Additional fieldwork and analyses may be needed to investigate changes to productivity rates within Kirtland's warbler habitat plantations. Furthermore, additional research on differences in productivity rates between short rotation and business-as-usual stands is needed. This further analysis could be incorporated with the findings presented to address questions about the site's ability to maintain the productivity levels simulated by LS-FVS across the time horizon.

Beyond the stand-level, further analysis could be implemented to assess the combinations of prescriptions needed to maintain the current habitat acreage while satisfying other goals. For example, the minimum number of acres needed in Short that produces the same habitat amount as BAU, and allow the remainder acres for Long or Thin. Setting minimum acreage can also be utilized for area constraint. For example, if there exists and upper acreage limit to KW habitat, and a breeding pair needs at least 80 acres (Wisconsin DNR 2014), then an annual harvestable acreage can be calculated. This would set constraints to optimize KW habitat with forest products or biomass supply.

A land manager could further adjust the thinning management regime to also account for the yield of forest products. The thinning schedules proposed could be altered such that the second thinning is abandoned, thus leaving more trees that would grow from pulpwood into sawlog size. Therefore, further optimization could produce results with higher product volumes, less silvicultural entries, or a combination that allows for 
production of sawlog-size trees and creates enough branches to supply natural regeneration.

\subsection{Acknowledgements}

The author would like to thank the USDA Agricultural and Food Research Initiative (AFRI) for funding. Also, a thank you to Michigan State University for assistance with field sampling, specifically Dr. David Rothstein, Daphna GadothGoodman, and Matt Gedritis. Finally, thank you to the field assistants Owen Souillere and Kate Martin for good jokes in the dense jack pine stands. 


\section{References}

Allen II, M.G., Burkhart, H.E. 2015. A comparison of alternative data sources for modeling site index in loblolly pine plantations. Canadian Journal of Forest Research. 45:1026-1033.

Anton-Fernandez, C., Burkhart, H.E., Strub, M., Amateis, R.L. 2011. Effects of Initial Spacing on Height Development of Loblolly Pine. Forest Science 57(3) 201-211.

Avery, T.E., Burkhart, H.E. 2001. Forest Measurements. New York: McGraw-Hill. Print.

Bailey, R.L., Clutter, J.L. 1974. Base-age invariant polymorphic site curves. Forest Science 20(2): pp. 155-159.

Burkhart, H.E.; Tome, M. 2012. Modeling Forest Trees and Stands. Dordrecht, Netherlands: Springer. Print.

Cao, Q.V., Durand, K.M. 1991. Site index curves for eastern cottonwood plantation in the Lower Mississippi Delta. Southern Journal of Applied Forestry 15(1): pp. 28-30.

Cao, Q.V. 1993. Estimating coefficients of base-age-invariant site index equations. Canadian Journal of Forest Research. 23:2343-2347.

Carmean, W.H., Hahn, J.T., Jacobs, R.D. 1989. Site index curves for forest tree species in the eastern United States. General Technical Report NC-128. St. Paul, MN: U.S. Dept. of Agriculture, Forest Service, North Central Forest Experiment Station

Clutter, J. L. Timber Management: A Quantitative Approach. New York, NY: Wiley, 1983. Print.

DeBell, D.S., Clendenen, G.W., Harrington, C.A. 1996. Tree growth and stand development in short-rotation Populus plantings: 7-year results for two clones at three spacings. Biomass and Bioenergy 11(4): pp. 253-269.

Deo, R.K. 2014. Application of an imputation method for geospatial inventory of forest structural attributes across multiple spatial scales in the Lake States, U.S.A. Dissertation, Michigan Technological University, 2014.

Deo, R.K., Froese, R.E. 2014. Redevelopment and verification of the large tree diameter increment model for LS and CS FVS. Project Final Report submitted to USDA Forest Service, Forest Management Service Center, Ft. Collins, CO. Challenge Cost Share Agreement 10-CS-11132425-258. $77 \mathrm{pp}$.

DesRochers, A., Tremblay, F. 2009. The effect of root and shoot pruning on early growth of hybrid poplars. Forest Ecology and Management. 258:2062-2067. 
Dixon, G.E., comps. 2002 (Revised: November 2, 2015). Essential FVS: A user's guide to the Forest Vegetation Simulator. Internal Rep. Fort Collins, CO: U. S. Department of Agriculture, Forest Service, Forest Management Service Center. 226p.

Dixon, G.E., Keyser, C.E., comps. 2008 (revised April 4, 2016). Lake States (LS) Variant Overview - Forest Vegetation Simulator. Internal Rep. Fort Collins, CO: U. S. Department of Agriculture, Forest Service, Forest Management Service Center. 50p.

Donner, D.M., Probst, J.R., Ribic, C.A. 2008. Influence of habitat amount, arrangement, and use on population trend estimates of male Kirtland's warblers. Landscape Ecology 23:467-480. DOI 10.1007/s10980-008-9208-9

ESRI. 2011. ArcGIS Desktop: Release 10. Redlands, CA: Environmental Systems Research Institute.

FIA. 2013. Forest inventory and analysis (FIA) national program: Data and tools. USDA Forest Service. [Online] http://apps.fs.fed.us/fiadb-downloads/datamart.html (Accessed on April 24, 2014).

Gevorkiantz, S.R. 1956. Site index curves for jack pine in the Lake States. USDA, Forest Service. Lake States Forest Experiment Station Technical Notes 463.

Gonzalez, R., Treasure, T., Wright, J., Saloni, D., Phillips, R., Abt, R., Jameel, H. 2011. Exploring the potential of Eucalyptus for energy production in the Southern United States: Financial analysis of delivered biomass. Part I. Biomass and Bioenergy 35:755766.

Goyal, G.C., Fisher, J.J., Krohn, M.J., Packwood, R.E., Olson, J.R. 1999. Variability in pulping and fiber characteristics of hybrid poplar trees due to their genetic makeup, environmental factors, and tree age. Tappi journal 82: 141-147.

Handler, R.M.; Shonnard, D.R.; Lautala, P.; Abbas, D.; Srivastava, A. 2014. Environmental impacts of roundwood supply chain options in Michigan: life-cycle assessment of harvest and transport stages. Journal of Cleaner Production 76 pp.64-73.

Hazlett, P.W., Morris, D.M., Fleming, R.L. 2014. Effects of Biomass Removals on Site Carbon and Nutrients and Jack Pine Growth in Boreal Forests. North America Forest Soils Conference, Whitefish, MT, 16-20 June 2013. Soil Science Society of America Journal 78:S183-S195.

Isebrands, J.G.; Karnosky, D.F. 2001 Environmental benefits of poplar culture. In: Dickmann, D.I. et al. eds. Poplar culture in North America. Ontario, Canada. NRC Research Press: pp. 207-218. 
Jenkins, J.C., Chojnacky, D.C., Heath, L.S., Birdsey, R.A. 2003. National-Scale Biomass Estimators for United States Tree Species. Forest Science 49(1):12-35.

Johansson, T. 2013. A site dependent top height growth model for hybrid aspen. Journal of Forestry Research. 24(4):691-698.

Johansson, T. 2011. Site index curves for poplar growing on former farmland in Sweden. Scandinavian Journal of Forest Research. 26:161-170.

Jones, E.A, Reed, D.D. 1991. Improved site index curves for young red pine plantations in the Northern Lake States. North Journal for Applied Forestry 8:59-63

Jonker, J.G.G., Junginger, M., Faaij, A. 2014. Carbon payback period and carbon offset parity point of wood pellet production in the South-eastern United States. GCB Bioenergy 6:371-389. doi:10.1111/gcbb.12056

Klockow, P.A., D'Amato, A.W., Bradford, J.B. 2013. Impacts of post-harvest slash and live-tree retention on biomass and nutrient stocks in Populus tremuloides Michx.dominated forests, northern Minnesota, USA. Forest Ecology and Management 291:278288. $<\mathrm{http}: / /$ dx.doi.org/10.1016/j.foreco.2012.11.001>

LeDuc, S.D., Rothstein, D.E. 2007. Initial recovery of soil carbon and nitrogen pools and dynamics following disturbance in jack pine forests: A comparison of wildfire and clearcut harvesting. Soil Biology \& Biochemistry 39:2865-2876.

MacKinney,A.L., Schumacher, F.X., Chaiken, L.F. 1937. Construction of yield tables for nonnormal Loblolly pine stands. Journal for Agricultural Research 54:531-545.

Manomet Center for Conservation Sciences. 2010. Massachusetts Biomass Sustainability and Carbon Policy Study: Report to the Commonwealth of Massachusetts Department of Energy Resources. Walker, T. (Ed.). Contributors: Cardellichio, P., Colnes, A., Gunn, J., Kittler, B., Perschel, R., Recchia, C., Saah, D., and Walker, T. Natural Capital Initiative Report NCI-2010-03. Brunswick, Maine.

Michigan Department of Natural Resources. 2016. Michigan DNR Kirtland's Warbler Operational Plan. Obtained by personal communication.

Michigan Department of Natural Resources. 2016. Timber Prospectuses. Accessed on 5 Jan. 2017. Available at $<$

http://www.michigandnr.com/ftp/forestry/tsreports/Prospectus/>

Michigan Department of Natural Resources. 2015. "Kirtland's Warbler." Department of Natural Resources. Web. 16 Dec. 2015. <http://www.michigan.gov/dnr/0,1607,7-15310370_12145_12202-32591--,00.html>. 
Michigan Department of Natural Resources, U.S. Fish and Wildlife Service, and U.S. Forest Service. 2015. Kirtland's Warbler Breeding Range Conservation Plan.

Miles, Patrick D.; Smith, W. Brad. 2009. Specific gravity and other properties of wood and bark for 156 tree species found in North America. Res. Note NRS-38. Newtown Square, PA: U.S. Department of Agriculture, Forest Service, Northern Research Station. $35 \mathrm{p}$.

Miner, C.L., Walters, N.R., Belli, M.L. 1988. A Guide to the TWIGS Program for the North Central United States. Gen. Tech. Rep. NC-125. U.S. Department of Agriculture, Forest Service, North Central Forest Experimental Station.

Mitchell, S.R., Harmon, M.E., O'Connell, K.B. 2012. Carbon debt and carbon sequestration parity in forest bioenergy production. GCB Bioenergy 4:818-827.

National Council for Air and Stream Improvement, Inc. (NCASI). 2013. A review of biomass carbon accounting methods and implications. Technical Bulletin No. 1015. Research Triangle Park, N.C.: National Council for Air and Stream Improvement, Inc.

Perin, J., Hébert, J., Brostaux, Y., Lejeune, P., Claessens, H. 2013. Modelling the topheight growth and site index of Norway spruce in Southern Belgium. Forest Ecology and Management 298: 62-70.

Pienaar, L.V.; Turnbull, K. J. 1973. The Chapman-Richards generalization of von Bertalanffy's Growth Model for basal area growth and yield in even-aged stands. Forest Science. 19(1): pp. 2-22(21).

Pinheiro, J., Bates, D., DebRoy, S., Sarkar, D., and the R Development Core Team, 2012. nlme: Linear and Nonlinear Mixed Effects Models. R package version 3.1103.

Pokharel, B., and Froese, R.E. 2008. Evaluating alternative implementation of the Lakes States FVS diameter increment model. Forest Ecology and Management 255:1759-1771.

Premer, M.I. 2015. Evaluating the long-term effects of logging residue removals in Great Lakes aspen forests. Open Access Dissertation, Michigan Technological University.

Probst, J.R., and Donnerwright, D. 2003. Fire and shade effects on ground cover structure rtland's warbler habitat. American Midland Naturalist Journal 149:320-334.

Pszwaro, J.L., D’Amato, A.W., Burk, T.E., Russell, M.B., Palik, B.J., Strong, T.F. 2013. Analysis of stand basal area development of thinned and unthinned Acer rubrum forests in the upper Great Lakes region, USA. Canadian Journal of Forest Research. 46:645-655. 
R Core Team (2015). R: A language and environment for statistical computing. R Foundation for Statistical Computing, Vienna, Austria. URL

http://www.R-project.org/.

Ragland, K.W., Aerts, D.J., Baker, A.J. 1991. Properties of wood for combustion analysis. Bioresource Technology 37:161-168.

Rittenhouse, T.A.G., MacFarland, D.M., Martin, K.J., Van Deelen T.R. 2012. Downed wood associated with roundwood harvest, whole-tree harvest, and unharvested stands of aspen in Wisconsin. Forest Ecology and Management 255:239-245.

doi:10.1016/j.foreco.2011.11.029

Rothstein unpublished field data 2016

Rothstein, D.E., Spaulding, S.E. 2010. Replacement of wildfire by whole-tree harvesting in jack pine forests: Effects on soil fertility and tree nutrition. Forest Ecology and Management 260:1164-1174.

Royne, F., Penaloza, D., Sandin, G., Berlin, J., Svanstrom, M. 2016. Climate impact assessment in life cycle assessments of forest products: implications of method choice for results and decision-making. Journal of Cleaner Production 116:90-99.

Rudolph, T. D. and Laidly, P. R. unnumbered pages in Burns, Russel M., and Barbara H. Honkala, tech. coords. 1990. Silvics of North America: 1. Conifers, 2. Hardwoods.

Agriculture Handbook 654. U.S. Department of Agriculture, Forest Service, Washington, DC. Vol.2, 877p.

$<$ https://www.na.fs.fed.us/spfo/pubs/silvics_manual/Volume_1/pinus/banksiana.htm>

Russell, M.B., D’Amato, A.W., Albers, M.A., Woodall, C.W., Puettman, K.J., Saunders, M.R., and VanderSchaaf, C.L. 2015. Performance of the Forest Vegetation Simulator in Managed White Spruce Plantations Influenced by Eastern Spruce Budworm in Northern Minnesota. Forest Science 61(4): 723-730.

Schumacher, F.X. 1939. A new growth curve and its application to timber-yield studies. Journal of Forestry 37:819-820.

Smith, James E.; Heath, Linda S.; Skog, Kenneth E.; Birdsey, Richard A. 2006. Methods for calculating forest ecosystem and harvested carbon with standard estimates for forest types of the United States. Gen. Tech. Rep. NE-343. Newtown Square, PA: U.S. Department of Agriculture, Forest Service, Northeastern Research Station. 216 p.

Soil Survey Staff, Natural Resources Conservation Service, United States Department of Agriculture. Web Soil Survey. Available online at https://websoilsurvey.sc.egov.usda.gov/. Accessed: 05/26/2016. 
Ter-Mikaelian, M.T., Colombo, S.J., Chen, J. 2015. The Burning Question: Does Forest Bioenergy Reduce Carbon Emissions? A Review of Common Misconceptions about Forest Carbon Accounting. Journal of Forestry 1113(1):57-68.

Tuskan, G.; West, D.; Bradshaw, H.D.; Neale, D.; Sewell, M.; Wheeler, N.; Megraw, B.; Jech, K.; Wiselogel, A.; Evans, R.; Carolyn, E.; Mark, D.; Dinus, R. 1999. Two highthroughput techniques for determining wood properties as part of a molecular genetics analysis of hybrid poplar and loblolly pine. Appl. Biochem. Biotech. 77: pp. 55-65.

U.S. Fish and Wildlife Service. Published: 14 Apr. 2014. "Kirtland's Warbler (Setophaga Kirtlandii)." Kirtland's Warbler Fact Sheet. Web. Accessed: 29 Mar 2017. $<$ http://www.fws.gov/midwest/endangered/birds/Kirtland/kiwafctsht.html>.

U.S. Fish and Wildlife Service. Environmental Conservation Online System. Web. 7 February 2017. < http://ecos.fws.gov/ecp/>

Walkinshaw, L.H. 1983. Kirtland's Warbler: The Natural History of an Endangered Species. Cranbrook Institute of Science, Bloomfield Hills, MI.

Wisconsin Department of Natural Resources. 2014. Wisconsin Kirtland's Warbler Species Guidance. Bureau of Natural Heritage Conservation, Wisconsin Department of Natural Resources, Madison, Wisconsin. PUB-ER-687.

Zalesny Jr., R.S., Bauer, E.O. 2007. Selecting and utilizing Populus and Salix for landfill covers: Implications for leachate irrigation. International Journal of Phytoremediation, 9:497-511.

Zalesny Jr., R.S., Headlee, W.L. 2015. Developing woody crops for the enhancement of ecosystem services under changing climates in the North Central United States. Journal of Forest and Environmental Science. 31(2): 78-90.

Zanchi, G, Pena, N., Bird, N. 2012. Is woody bioenergy carbon neutral? A comparative assessment of emissions from consumption of woody bioenergy and fossil fuel. GCB Bioenergy 4:761-772. 